\title{
3.19 THE UPPER PALAEOLITHIC OF EUROPE
}

\author{
JOÃO ZILHÃO
}

\section{Concept and Definition}

Over the last quarter century, discussions of the emergence of the Upper Palaeolithic (UP) have become intimately associated with disappearance of "archaic" humans and rise of "modernity" issues. As a consequence of the gradual blurring of previously perceived contrasts with the Middle Palaeolithic (MP) in technology, subsistence and site structure (Bar-Yosef \& Kuhn I999; Speth 2004), the definitional significance of ornaments and art was emphasised, with one strand of scientific opinion arguing that their sudden emergence in the European record in tandem with the replacement of Neanderthals by modern humans, about 40,000 years ago, could not be a coincidence (e.g., Klein 2003; Mellars 2004a, 2005). In this view, both processes ought to be explained by (a) the emergence of modern humans in Africa being a speciation event, (b) Neanderthals being a different species with less evolved capabilities, (c) art and personal ornamentation being material proxies for symbolic thinking and language and (d) the lack of such proxies in the MP proving that its makers were fundamentally different from present-day humans in biology, cognition and culture.

This view of the emergence of the UP as a "Human Revolution" (Mellars \& Stringer 1989) has since been shown to be inconsistent with the empirical evidence in crucial respects, namely, (a) in Africa, art remains unknown for more than 150,000 years after anatomical modernity first appears in the palaeontological record, which questions mechanistic explanations of the emergence of the phenomenon as a straightforward and immediate consequence of the acquisition of cognitive capabilities provided by neurological changes putatively associated with the changes in skeletal morphology; (b) in the Maghreb, personal ornaments date to about 90,000 years ago, when the region was inhabited by the anatomically archaic Aterian people, which further questions the notion of a direct link of causality between "modern anatomy" and "modern cognition"; (c) in Europe, the earliest figurative art postdates modern human immigration by almost five millennia, which questions cognitive explanations of the Neanderthals' demise; (d) in Iberia, by 50,000 years ago, about ten millennia before moderns are first recorded in Europe, MP Neanderthals used marine shell beads and complex cosmetic recipes; and (e) in France, by 60,000 years ago, Neanderthals were burying their dead with grave-goods (e.g., the engraved bone associated with the La Ferrassie I adult individual) and architecture (e.g., the slab decorated with cupules covering the burial pit of the La Ferrassie 6 child) (Zilhão 200I, 2007, 20II; d'Errico 2003; d'Errico et al. 2003a; Wolpoff et al. 2004; Trinkaus 2005a; Bouzouggar et al. 2007; d'Errico et al. 2009; Zilhão et al. 2010a).

A string of key palaeontological revelations accompanied this transformation of the archaeological landscape, including (a) the discovery of new fossils, such as the Lagar Velho child from Portugal (Duarte et al. I999; Zilhão \& Trinkaus 2002) or the Oase I mandible and Oase 2 cranium from Romania (Trinkaus et al. 2003; Rougier et al. 2007; Zilhão et al. 2007), and (b) the secure dating and reanalysis of long-forgotten material, such as the Cioclovina and Muierii crania from Romania (Soficaru et al. 2006, 2007; Dobos et al. 2010) or the sample from Mladeč, in the Czech Republic (Teschler-Nicola et al. 2006). All of these fossils display diagnostic Neanderthal traits, suggesting significant admixture at the time of contact (Trinkaus 2007). This inference has since been corroborated by the outcome of the Neanderthal genome project, which found a Neanderthal contribution in the genome of extant humans - estimated to be of $1 \%$ to $4 \%$ and significantly higher in Eurasians than in Africans (Green et al. 2010). The combined palaeontological and palaeogenetical evidence thus shows that the disappearance of the Neanderthals, although construable as a replacement process in a long-term, evolutionary sense, was not a process of extinction without descent. Moreover, it makes it clear that Neanderthals were also Homo sapiens, not a separate species, and that the processes of population dispersal, extinction and assimilation that occurred at the time of emergence of the European UP must be explained in terms of the operation of environmental, demographic, cultural and contingent factors - they are a part, not the cause, of what happened at this particular point in (pre-)history.

Given this recent evidence, does it still make sense to maintain a conceptual distinction between the MP and the UP? In Europe, yes, for a number of reasons. Firstly, in terms of technology (Fig. 3.I9.I; Bar-Yosef \& Kuhn 1999; Meignen \& Bar-Yosef 2004), the traditional definition of the UP remains operationally valid because (a) across the continent, the stone tool assemblages of 

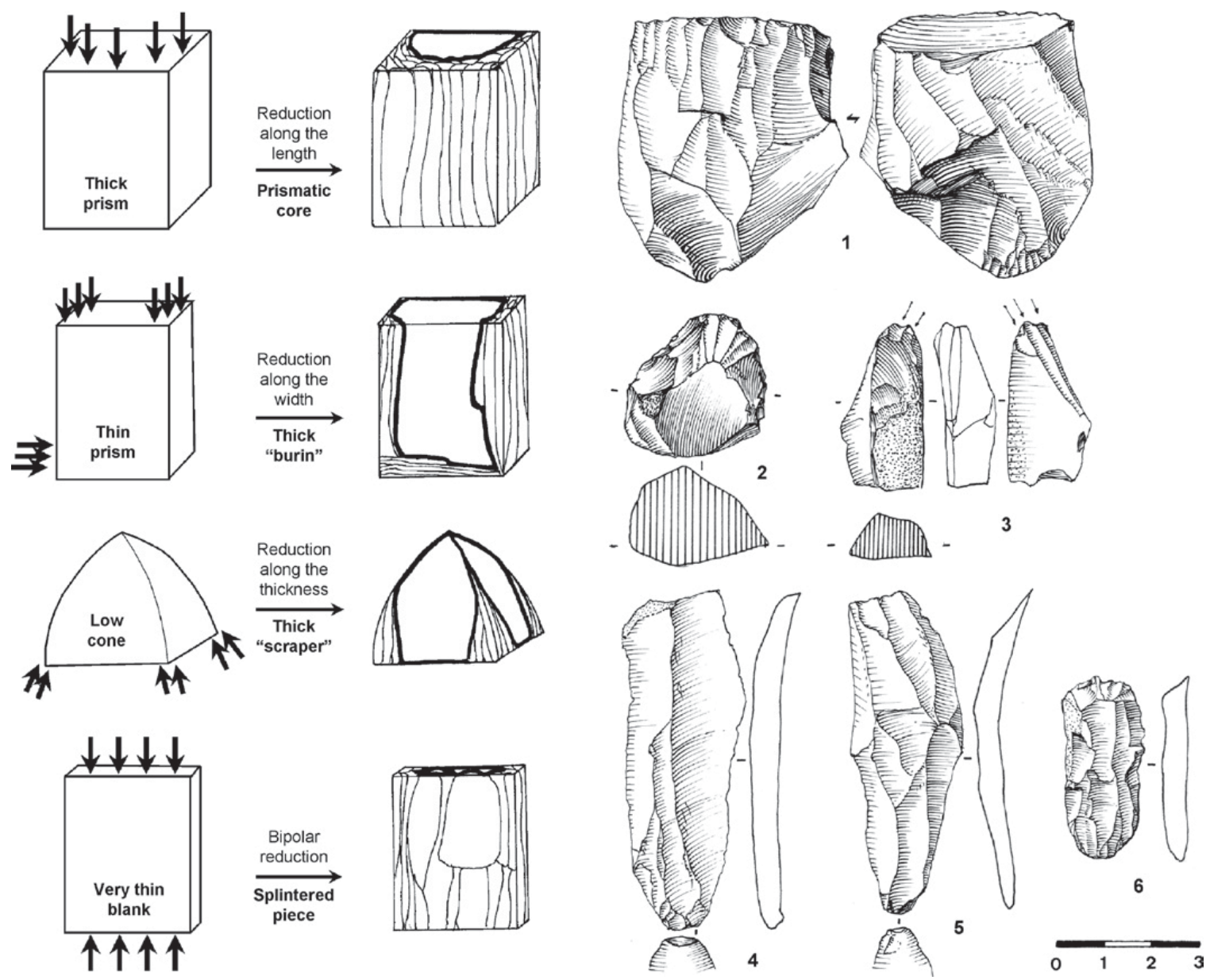

Figure 3.I9.I. Upper Palaeolithic stone tool technology. Left: four modes of volumetric reduction and the corresponding core types. Right: Upper Palaeolithic flint artifacts from the site of Fonte Santa, Portugal (I. prismatic blade/bladelet core; 2. carinated "scraper"; 3. thick "burin"; 4-5. unretouched blade blanks; 6. end-scraper). (From Zilhão 1997.)

the later part of the MP were flake-based, whereas, after about forty-five thousand years ago, blade/bladelet production became predominant, if not exclusive, and remained so for thirty millennia; (b) such blade/bladelet blanks were obtained in the framework of volumetric core reduction schemes, while the Levallois method, characteristic of the MP, was entirely abandoned, even for the production of flake blanks; (c) as a result, the domestic component of retouched tool assemblages became dominated by end-scrapers and retouched blades instead of side-scrapers, notches and denticulates; (d) a component of points and barbs designed to be mounted on projectile tips and shaped to recognisable templates became readily apparent (probably in relation to the widespread adoption of complex composite tools requiring standardised blanks); and (e) implements made of bone and antler became ubiquitous at about the same time, even in those parts of the continent where wood was never in short supply, not even when climatic conditions were at their harshest. Secondly, in terms of demography, society and culture, the evidence for territoriality and identity, both individual and social, rare prior to $\sim 45$, ooo years ago, became widespread thereafter and until the end of the Palaeolithic (Gamble 1983, 1999; Vanhaeren \& d'Errico 2006).
After a review of current knowledge concerning the climatic and environmental background, this chapter will discuss issues of human ecology, culture and history. Given the limitations of space, the geographical and chronological coverage is of necessity imbalanced, and the emphasis will lie on describing and proposing interpretations for perceived general patterns, using specific case studies to support the arguments, rather than on the illustration of regional or temporal particularities. The aim is to bring into focus what the UP as a whole represents in evolutionary terms by comparison with preceding times, namely where (a) technological innovation and adaptive success relate to demographic growth and social complexification, and (b) these and related factors set a base line for the momentous developments that led to the emergence of food production in the later prehistory of Europe and the Greater Mediterranean.

Throughout, calendar ages before present will be used (i.e., when relying upon radiocarbon results, after calibration; Reimer et al. 2009). The location of all sites mentioned in the text is given in Map 3.I9.I, and the units of analysis are the different techno-complexes recognised in the literature (Table 3.I9.I), grouped into four major phases: Transitional, 


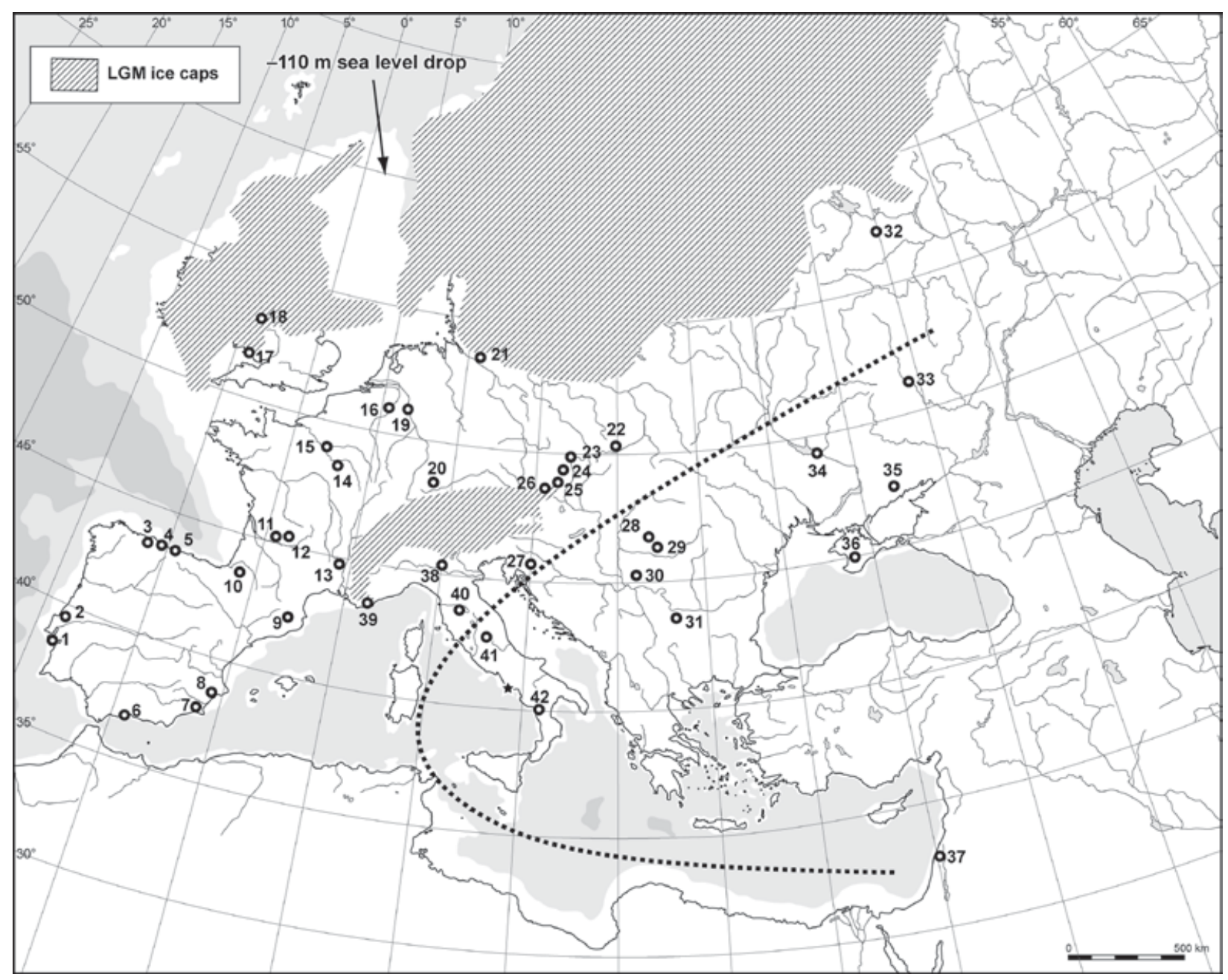

MAP 3.I9.I. Map of Europe, showing the location of sites mentioned in the text. The star marks the volcano near Naples that exploded $\sim 39,300$ years ago, and the dotted line marks approximate limits of the corresponding ash fall. The ice caps are represented at maximum extension, during the LGM; in MIS 3 , the Fennoscandinavian sheet retreated beyond $60^{\circ} \mathrm{N}, \mathrm{Britain}$ and Ireland were deglaciated, and the Alpine cap was smaller. Portugal: I. Figueira Brava; 2. Anecrial, Caldeirão, Fonte Santa and Lagar Velho. Spain: 3. La Viña and El Sidrón; 4. Altamira; 5. El Mirón; 6. Nerja; 7. Palomas; 8. Bolomor, Cendres and Parpallò; 9. L’Arbreda. France: Io. Isturitz; II. Saint-Germain-la-Rivière; I2. Combe Saunière, Flageolet I, Fourneau du Diable, La Madeleine, Lascaux, Le Placard and Pont d'Ambon; I3. Chauvet; I4. Grotte du Renne; I5. Pincevent and Verberie. Belgium: I6. Spy. United Kingdom: 17. Paviland; I8. Kendrick's. Germany: I9. Bonn-Oberkassel and Neanderthal; 20. Geissenklösterle; 21. Stellmoor. Poland: 22. Piekary IIa; Czech Republic: 23. Mladeč; 24. Brno-Bohunice and Předmostí; 25. Dolní Věstonice and Pavlov; Austria: 26. Willendorf. Croatia: 27. Vindija. Romania: 28. Cioclovina; 29. Muierii; 30. Oase and Tincova. Bulgaria: 3r. Kozarnika. Russia: 32. Sungir; 33. Kostenki. Ukraine: 34. Mezhirich; 35. Amvrosievka. 36. Buran Kaya III and Siuren. Israel: 37. Ein Mallaha, Hayonim, Kebara. Italy: 38. Fumane; 39. Mocchi; 40. Bilancino; 4I. Pozzo; 42. Romito.

Early, Full and Final. The first phase begins some time between fifty thousand and forty-five thousand years ago with a period during which European Neanderthals experimented with novel technological systems in regionally diverse ways, and ends with the Protoaurignacian intrusion, which at present seems to be devoid of local roots and thus may well represent the archaeological signature of the first wave of modern human immigration. The second phase, which begins with the Early Aurignacian, about forty thousand years ago, witnesses the resolution of the complex processes of population interaction inherited from the Transitional Period, eventually leading to the absorption of the last of the Neanderthals and concluding with the emergence of the Gravettian, at a time, about thirty-five thousand years ago, when all elements of the Upper Palaeolithic "package" were firmly in place across the entire continent. The third phase corresponds to the development of these societies as they successfully coped with twenty millennia of full glacial environments, and the fourth comes with deglaciation, when, over only about three thousand years, European hunter-gatherers had to respond to a relatively rapid transition to the full interglacial environments of the Holocene. 
TABle 3.I9.I. Schematic culture-stratigraphy of the Upper Palaeolithic of Europe, and lower chronological boundaries of its different subdivisions (approximate; calibrated ages rounded to the nearest century). For eastern Europe, where no consensus on cultural taxonomy exists for the Full Phase, site horizons typical of the corresponding time slices are indicated.

\begin{tabular}{|c|c|c|c|c|c|c|}
\hline Phase & ${ }^{\mathrm{I} 4} \mathrm{C}$ BP & cal BP & Western Europe & $\begin{array}{l}\text { Northern and } \\
\text { Central Europe }\end{array}$ & Italy and SE Europe & Eastern Europe \\
\hline Final & $\mathrm{I} 2,500$ & $\mathrm{I} 4,600$ & $\begin{array}{l}\text { Creswellian (England) } \\
\text { Azilian-Laborian } \\
\quad \text { (France, Cantabria) } \\
\text { Epimagdalenian } \\
\text { (Iberia) }\end{array}$ & $\begin{array}{l}\text { Ahrensburgian and } \\
\text { Swiderian } \\
\text { Hamburgian and } \\
\text { Federmessergruppen }\end{array}$ & Romanellian (Italy) & \\
\hline \multirow[t]{3}{*}{ Full } & $\begin{array}{l}17,000 \\
19,000\end{array}$ & $\begin{array}{l}20,200 \\
22,700\end{array}$ & $\begin{array}{l}\text { Magdalenian } \\
\text { Badegoulian (France) } \\
\text { Solutreogravettian } \\
\quad \text { (SW Iberia) }\end{array}$ & Magdalenian & Tardigravettian & $\begin{array}{l}\text { Mammoth- } \\
\text { dwellings } \\
\text { culture }\end{array}$ \\
\hline & 21,000 & 25,000 & $\begin{array}{l}\text { Upper Solutrean } \\
\text { Middle Solutrean } \\
\text { Lower Solutrean }\end{array}$ & & & \\
\hline & 30,000 & 34,700 & Gravettian & $\begin{array}{l}\text { Willendorf-Kostenkian } \\
\text { Pavlovian }\end{array}$ & Gravettian & $\begin{array}{l}\text { Kostenki/Avdeevo } \\
\text { Molodovan }\end{array}$ \\
\hline Early & 35,000 & 40,300 & Aurignacian & Aurignacian & Aurignacian & Aurignacian \\
\hline \multirow[t]{2}{*}{ Transitional } & $3^{6,500}$ & $4 \mathrm{I}, 600$ & Protoaurignacian & $\begin{array}{l}\text { Lincombian/ } \\
\text { Jerzmanovician }\end{array}$ & Protoaurignacian & $\begin{array}{l}\text { Spitsynian } \\
\text { Streletskayan }\end{array}$ \\
\hline & $>4 \mathrm{I}, 000$ & $>44,700$ & Châtelperronian & $\begin{array}{l}\text { Altmühlian/Szeletian } \\
\text { Bohunician }\end{array}$ & $\begin{array}{l}\text { Uluzzian } \\
\text { (Italy, Greece) } \\
\text { Bachokirian } \\
\text { (Bulgaria) }\end{array}$ & \\
\hline
\end{tabular}

\section{Climate and Environments}

For most of the 2oth century, the rhythmic succession of advances and retreats of the Alpine glaciers provided a backbone for the stratigraphy of terrestrial Quaternary deposits, with both the MP and the UP falling during the latest period of advance, the so-called Würm glaciation. However, the palynological study of peat bogs and archaeological sites showed that this last glaciation had not been climatically homogeneous; interstadials, periods of warmer conditions characterised by an expansion of arboreal pollen types and named after particular sampling localities bearing the relevant pollen evidence (e.g., Hengelo, Denekamp), had alternated with colder, stadial periods.

Over the last thirty years, this Alpine/palynological system has been replaced by a chronostratigraphic framework that, although using the same glacial/interglacial and stadial/interstadial terminology, is built upon a combination of micropalaeontological, palynological and isotopic data derived from cores drilled into deep sea sediments and the polar ice caps (Bradley 1999; Sánchez-Goñi \& Harrison 2010; Wolff et al. 2010). The higher subdivision, the Marine Isotope Stage (MIS), is based on the fluctuation observed over time in the proportions of the different oxygen isotopes present in the tests of marine foraminifera; this fluctuation is a proxy for climate because it reflects variation in the relative size of Earth's two main water reservoirs, the oceans and the ice caps. Within each MIS, climatic fluctuations on a millennial scale are detected on the basis of the variation of the heavy isotope ${ }^{\mathrm{I}} \mathrm{O}-\mathrm{a}$ proxy for local temperature conditions - across the annual or decadal layers of ice accumulated in Greenland ice cores (Fig. 3.19.2); such oscillations are known as Dansgaard-Oeschger (D-O) cycles, each comprising a colder (Greenland Stadial, or GS) and a warmer phase (Greenland Interstadial, or GI). The duration of the GIs and the abrupt nature of the warming events that mark their beginning (typically involving temperature rises in the order of $5-10^{\circ} \mathrm{C}$ in only a few decades) cause a vegetational response (e.g., the expansion of thermophyle taxa) that can be tracked in the pollen contents of both marine and continental deposits and is in phase with the oxygen data - proving that these do record climate change on a global scale and validating the worldwide use of MIS stages and D-O cycles for chronostratigraphic purposes.

The oxygen isotope stratigraphy of the last fifty thousand years of the Pleistocene is given in Table 3.19.2, where, additionally, the different stadials that are associated with episodes of iceberg discharge in the North Atlantic (so-called Heinrich Stadials, denoted by the presence of ice-rafted debris in marine cores drilled as far south in the Atlantic as $40^{\circ} \mathrm{N}$ ) are also indicated. MIS 4 and MIS 2 are the periods of maximum ice volume, when the coldest and driest climates and the harshest environmental conditions were present, and over extended periods of time (e.g., GS I8/I9 and GS 2/3, the latter corresponding to the Last Glacial Maximum or LGM) (Harrison \& 


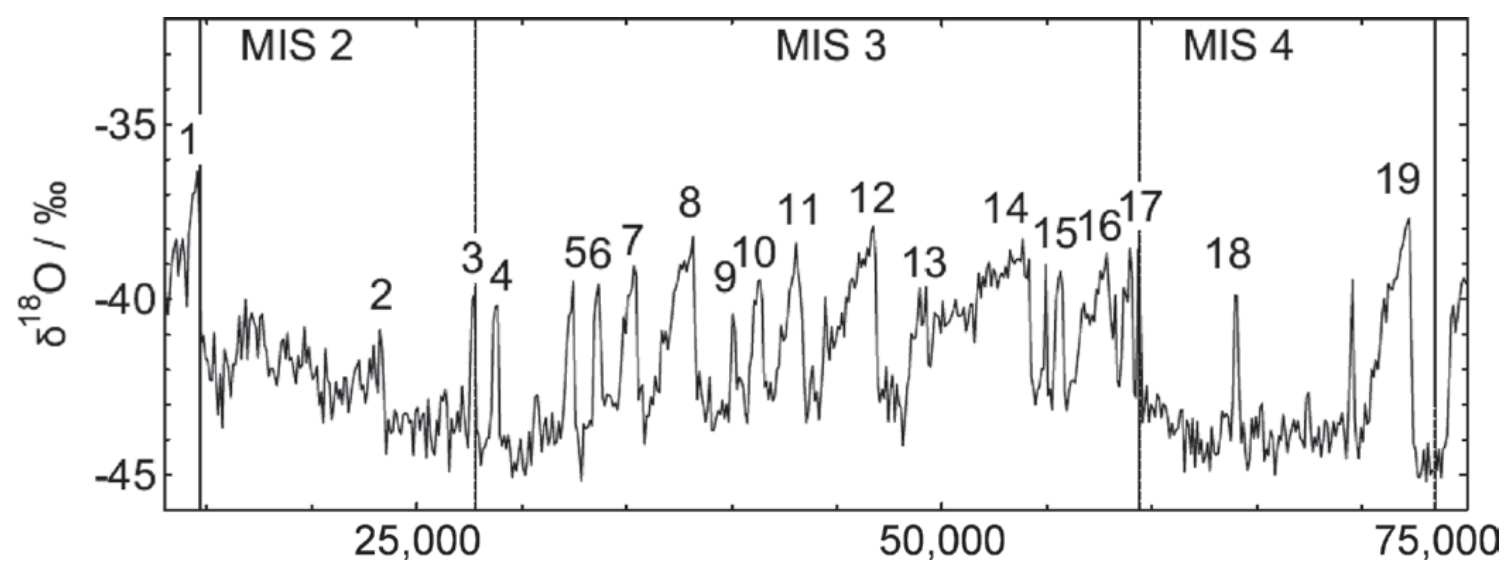

FIGURE 3.I9.2. Dansgaard-Oeschger events of MIS 2-4 in the NGRIP ice core, Greenland. The numbers mark the different Greenland Interstadials (GI) recognised in this time interval.

Sánchez-Goñi 20I0). In Europe, beyond a tundra belt developed around ice sheets that extended as far south as Wales, northern Germany and northern Poland, the pollen records indicate a ubiquitous herbaceous and shrubland landscape, with tree cover restricted to open sclerophyll woodlands in western Iberia, Italy and the Balkans, and temperate taxa surviving only in isolated mountain refugia of these meridional regions.

Such steppe-like environments fed a rich and varied herbivorous fauna, featuring herds of mammoth, woolly rhino, bison, reindeer and horse. In hilly country, ibex and chamois which, due to the descent of the snow line caused by mountain glaciation, could then be found at relatively low elevations complemented the range of game. At times of extreme aridity, even such species typical of the central Asian steppe as the saiga antelope expanded into Europe as far west as France. However, some of these taxa (namely, mammoth, bison, reindeer and woolly rhino) never penetrated deep into the southernmost peninsular regions, where red deer and aurochs remained the primary game throughout the UP.

In interstadial times, European environments became more heterogeneous, but vegetation response to the warming events varied markedly with latitude and continentality (Fletcher et al. 20I0). Typically, (a) polar deserts were replaced by grassland and shrub tundra in northwestern Europe and by shrub- and forest-tundra in northeastern Europe, (b) boreal forests greatly expanded in the Alpine region and in eastern Europe, where elements thereof have been found to thrive close to the present-day limit of the taiga $\left(\sim 70^{\circ} \mathrm{N}\right)$, (c) in southern Europe, open temperate forests expanded, but not beyond $\sim 45^{\circ} \mathrm{N}$, and (d) in western Europe, open boreal forests formed a latitudinal band of $\sim \mathrm{I} 5^{\circ}$ over which took place a gradual transition to tundra.

Interstadials also varied - in duration, intensity and vegetation response. For instance, individual D-O oscillations lasted on average $\sim 3250$ years during MIS 2 and MIS 4 , but only about one-third of that (II30 years) during the intervening MIS 3 , a stage of intermediate-sized ice caps and greater climatic instability. Two particular MIS 3 interstadials, GI 12 and GI 8, had very steep, more than $10^{\circ} \mathrm{C}$ temperature rises and longer durations, as much as 2600 years in the case of GI I2. The latter, moreover, was separated by a relatively short stadial from the next interstadial (GI II), itself one millennium-long. Although punctuated by the GS II/I2 cold event, this period of time also experienced, on average, the highest temperatures recorded over Greenland between about fifty thousand years ago and the end of the Pleistocene. It is probably not a coincidence that the transition to the UP began in western Eurasia exactly at this time. Likewise, the persistence of the MP until the end of GI 8 in Iberian regions to the south of the Ebro drainage (Zilhão I993; Zilhão et al. 20rob) must also have environmental underpinnings, as the pollen records show that this cultural boundary was located along a major gradient at $\sim 40^{\circ} \mathrm{N}$ (in the GI 8 sections of high-resolution marine cores of the Iberian border, warm temperate and temperate taxa are in the range of $30 \%$ to $55 \%$ below that latitude and of $10 \%$ to $15 \%$ above it; Fletcher et al. 2010).

\section{Subsistence and Settlement}

Upper Palaeolithic Europeans are often portrayed as ancient versions of today's Caribou Eskimo, living in adverse tundra environments and depending on the hunting of reindeer, from whose meat, skin, antlers and bones they would have derived not just the means of their alimentary subsistence but also the raw materials for the manufacture of clothes, shoewear, shelter, and a diverse range of tools. This notion reflects the fact that most of what we know about the period comes from sites in France and other areas of western Europe characterised by the abundance of reindeer remains, and in that sense the image is not entirely incorrect; but it is distorted, and, despite its popularity, the related scientific claim that the Upper Palaeolithic was characterised by specialised hunting economies, ones that concentrated on particular species (e.g., reindeer) to the detriment of other potential resources, is not supported by the evidence (Mellars 1973, 2004b; Grayson \& Delpech 2002).

Reindeer are indeed overwhelmingly dominant in many Upper Palaeolithic faunal assemblages, both early and late, but dominance does not necessarily reflect exclusive reliance. 
TABLE 3.19.2. Oxygen-isotope chronostratigraphy of the last sixty thousand years of the Pleistocene (Sánchez-Goñi \& Harrison 2010; Wolff et al. 2010).

\begin{tabular}{|c|c|c|c|c|c|c|}
\hline $\begin{array}{l}\text { Marine } \\
\text { Isotope } \\
\text { Stages (MIS) }\end{array}$ & $\begin{array}{l}\text { Greenland } \\
\text { D-O Cycles }\end{array}$ & $\begin{array}{l}\text { Heinrich } \\
\text { Stadial (HS) }\end{array}$ & $\begin{array}{l}\text { Beginning } \\
\text { (cal вр) }\end{array}$ & $\begin{array}{l}\text { Duration } \\
\text { (Years) }\end{array}$ & $\begin{array}{l}\text { Temperature } \\
\text { Jump }\left({ }^{\circ} \mathrm{C}\right)\end{array}$ & $\begin{array}{l}\text { Major Events in European } \\
\text { Culture History }\end{array}$ \\
\hline \multirow[t]{3}{*}{ I } & \multirow{2}{*}{\multicolumn{2}{|c|}{$\begin{array}{l}\text { Lower boundary of Holocene } \\
\text { Younger Dryas }\end{array}$}} & II, 653 & - & $10 \pm 4$ & Mesolithic \\
\hline & & & & & & Emergence of a regionally diverse \\
\hline & GI I & & 14,642 & I900 & $\mathrm{II} \pm 3$ & "Epipalaeolithic” \\
\hline \multirow[t]{4}{*}{2} & GS I/2 & I & & & & Northern and central Europe devoid of \\
\hline & GI 2 & & 23,290 & IOO & - & human settlement between $\sim 28,000$ and \\
\hline & GS 2/3 (LGM) & 2 & & & & $\sim$ I8, о०о cal вР \\
\hline & GI 3 & & 27,730 & 300 & - & \\
\hline \multirow[t]{18}{*}{3} & $\mathrm{GS}_{3} / 4$ & & & & & \\
\hline & GI 4 & & 28,850 & 300 & $12 \pm 5$ & \\
\hline & $\mathrm{GS}_{4} / 5$ & 3 & & & & \\
\hline & $\begin{array}{l}\text { GI } 5 \\
\text { GS } 5 / 6\end{array}$ & & 32,450 & 500 & $7 \pm 5$ & \\
\hline & $\begin{array}{l}\text { GI } 6 \\
\text { GS } 6 / 7\end{array}$ & & 33,690 & 400 & $7 \pm 5$ & \\
\hline & $\begin{array}{l}\text { GI } 7 \\
\text { GS } 7 / 8\end{array}$ & & 35,430 & 700 & $9 \pm 3$ & $\begin{array}{l}\text { Late Aurignacian spread across all of } \\
\text { Europe }\end{array}$ \\
\hline & GI 8 & & 38,170 & 1600 & $\mathrm{II}(+3 /-6)$ & Middle Palaeolithic persistence to the \\
\hline & GS $8 / 9$ & 4 & & & & south of the Ebro drainage; emergence \\
\hline & $\begin{array}{l}\text { GI } 9 \\
\text { GS 9/IO }\end{array}$ & & 40,110 & 300 & $9(+3 /-6)$ & of the Aurignacian elsewhere in Europe \\
\hline & $\begin{array}{l}\text { GI Io } \\
\text { GS IO/II }\end{array}$ & & $4 \mathrm{I}, 4 \mathrm{IO}$ & 700 & II. $5(+3 /-6)$ & $\begin{array}{l}\text { Protoaurignacian intrusion } \\
\text { "Transitional" industries emerge and }\end{array}$ \\
\hline & $\begin{array}{l}\text { GI II } \\
\text { GS II/I2 }\end{array}$ & & 43,290 & 1000 & $15(+3 /-6)$ & $\begin{array}{l}\text { develop in the Balkans, in Italy and in } \\
\text { central and western Europe }\end{array}$ \\
\hline & GI I2 & & 46,810 & 2600 & $12 \pm 2.5$ & \\
\hline & GS I2/I3 & 5 & & & & Middle Palaeolithic \\
\hline & $\begin{array}{l}\text { GI I3 } \\
\text { GS I3/I4 }\end{array}$ & & 49,230 & - & $8(+3 /-6)$ & \\
\hline & $\begin{array}{l}\text { GI I4 } \\
\text { GS I4/I5 }\end{array}$ & & 54,170 & - & $\mathrm{I} 2 \cdot 5(+3 /-6)$ & \\
\hline & $\begin{array}{l}\text { GI I5 } \\
\text { GS I5/I6 }\end{array}$ & & 55,750 & - & $\mathrm{IO}(+3 /-6)$ & \\
\hline & $\begin{array}{l}\text { GI I6 } \\
\text { GS I6/I7 }\end{array}$ & & 58,230 & - & $9(+3 /-6)$ & \\
\hline & GI I7 & & 59,390 & - & $\mathrm{I} 2(+3 /-6)$ & \\
\hline \multirow[t]{3}{*}{4} & GS I7/I8 & 6 & & & & \\
\hline & $\begin{array}{l}\text { GI I8 } \\
\text { GS I8/I9 }\end{array}$ & & 64,045 & 300 & $\mathrm{II} \pm 2.5$ & \\
\hline & GI ig & & 72,280 & 2000 & $16 \pm 2.5$ & \\
\hline
\end{tabular}

For instance, if a given archaeological locality corresponds to a place where herds were killed in large numbers, then the majority, if not the totality, of the faunal assemblage excavated therein will naturally comprise bones of the target species. And if, for reasons related to preservation or research history biases, such kinds of sites dominate the archaeological record of a given period or region, interpretations of the evidence can easily enough become imprinted with the notion of an economy based on the exploitation of a single species. However, such a notion would be based on a body of data that sampled a very small part of the overall settlement and subsistence system. In fact, when zooarchaeological analyses are conducted on a regional scale and bear in mind the evidence concerning raw-material economy, tool use and site structure, a more complex picture of reindeer exploitation becomes apparent, as illustrated by a number of case studies.

The Paris Basin has yielded some of the best-known UP sites of Europe, remarkable for their Pompeii-like preservation of 
living floors. Two of them stand out for their abundant faunal remains: Pincevent (level IV-20) and Verberie, both Upper Magdalenian sites dated to $\sim$ I5, 000 cal BP and where, for reindeer, the minimum numbers of individuals are of seventy-six and ninety-seven, respectively (Enloe 2003). Both sites are immediately adjacent to major rivers and contain tool assemblages dominated by hunting weaponry, suggesting that they relate to the practice of ambushing reindeer herds when they are slowest and most vulnerable, that is, when crossing a ford. The analysis of the juvenile dentitions places the kills in a tight window of time - early October - while the age profiles of the assemblages show that young males and prime-age adults of both sexes were selectively targeted. At Pincevent, selection is also apparent in body part representation, with vertebral columns being completely absent, indicating a transported assemblage, whereas they are common at Verberie, indicating that the site corresponds to a hunting station.

The pattern of bone refits is consistent with this evidence: at Pincevent, it suggests household hearths and the kinds of food-sharing practices that, among modern hunter-gatherers, are seen between close kin (the distribution of the byproducts of marrow consumption episodes is restricted to individual features, while that of meat-bearing body parts embraces the entire camp, with the greatest amount of exchange occurring between immediate neighbours); at Verberie, in contrast, the hearths relate to specialised activities (food preparation and stone tool manufacture), and the bone distributions form the kinds of dumps suggestive of carcass preparation and some on-site consumption that one would expect from a male task group operating at a kill-site.

The characteristics of these sites are strongly suggestive of a strategy whereby reindeer were intercepted during their autumn migration, when the animals attain maximum weight and fat content, with the food thus obtained then being processed for consumption over the following winter (Enloe 2003). The evidence from contemporary localities found elsewhere in the region is consistent with this interpretation, but what were the hunters doing in spring and summer, when reindeer, after coming back up north, would have dispersed into small groups scattered about and could not be taken with the intercept strategy used in the autumn? Because other herd animals, such as horse, would then also be more loosely distributed in the landscape, humans must have resorted, in the warmer seasons, to encounter-hunting of anything they could get, with horse, given the larger size of the meat package, being preferred. The small numbers of horse, mammoth, hare, ground squirrel and birds recovered at Pincevent and Verberie can be seen as corroborating this inference in that they probably correspond to the food brought in to the camps, or obtained there while waiting for the reindeer to arrive. The reason why, for storage, reindeer were preferred over horse despite their smaller body size may have resided in (a) the predictability of their migration routes and (b) the fact that the bones of reindeer yield much more fat-rich marrow, a nutritionally critical resource in the last glacial winters of tundra regions situated at the northern limit of the human range.
This Paris Basin evidence is consistent with that from the Magdalenian of similar latitudes, namely, southwest Germany and northern Switzerland, where the pattern is one of autumn and winter hunting of reindeer and summer hunting of horse (Weniger 1982, 1987). Farther to the south, however, hunters exploited reindeer in rather a different way. In southwestern France (Fontana 2000), most sites were either occupied continuously throughout the year or intermittently but at all seasons; however, reindeer kills - mostly of adult females, juveniles and subadults - were strongly concentrated in winter and spring. This pattern reflects the social structure of the herds, which, after the period of rut, split for the winter into groups with exactly the age/sex composition seen in the hunted assemblages, while adult males become widely scattered, making their hunt less effective (in addition to less desirable, as males may become as much as $25 \%$ thinner in winter and lose their antlers in December, when those of females reach their maximum density). In these more meridional regions, therefore, reindeer would have been hunted (with an encounter strategy, at random, and continuously) during the seasons when they formed substantial aggregates, with no selection of the targets and no processing for storage and deferred consumption. Because none of the analysed sites feature exclusively summer occupations, the nature of the hunters' response to the estival scattering of the herds remains unclear. However, that reindeer continued to be present in the sites' catchments is proven by the massacred antlers of adult males found therein, which possibly indicates ambush hunting of individuals targeted for that particular resource.

As most herd animals, not just reindeer, disperse during the warm season, it is likely that, in southwestern France, adults of the principal game species were pursued in much the same way, and some sites have indeed yielded evidence that horses were hunted all year round, including summer. The data for saïga antelope in the Gironde, an area where, during GS I/2, this other herd species contributed significantly to human diets, suggest, however, a seasonal rotation of the hunts, with saïga targeted in the spring (perhaps in a migration intercept framework), horse in the summer and reindeer in the winter (Costamagno 2000, 200I). In this particular region and at this particular time, their abundance in the environment and markedly migratory behaviour may have led to a particular emphasis on saiga and the adoption of the kinds of strategies that characterise the Paris Basin and other regions farther to the north. In the Dordogne, some sites also exist where human occupation is documented throughout the year and such a seasonal round of the hunts may have been followed. This is, for instance, the case with the LGM Solutrean levels of the Combe Saunière Cave, where, however, the overall annual balance remains tipped in favour of reindeer, even if, when meat-weight, not the number of individuals taken, is considered, horse and bovids come close in importance (Castel et al. 2006).

The reindeer-dominated aspect of the classic UP sites of the middle Dordogne drainage is thus largely an artifact of their being mostly winter camps. Under the "specialised hunters" perspective, this dominance should imply that, in the summer, (a) reindeer left the region in search of fresh pastures at 
higher elevation and (b) the hunters adopted a similar seasonal schedule and followed the herds in order to be able to continue feeding off them (e.g., Gordon I988). This notion is inconsistent with the evidence for summer activity in the area and is also unsupported by the Pyrenean sites, which suggest shortdistance, lowland-upland altitudinal displacements rather than long-distance migrations (Delpech I983; Straus 1995). The reason why, in southern France, reindeer were rather territorial and behaved quite differently from what would one imagine on the basis of present-day analogues from the North American Arctic may have resided in the complex topography of the area which, coupled with its lower latitude, generated a more diverse set of environments, ones where the animals were able to find food at all seasons of the year. In a more continental setting, a possible exception to this territoriality of western Europe's last glacial reindeer is the pattern of highly seasonal movement of both the herds and their hunters that seems to have existed between the high valleys of the Massif Central, where no winter sites are known, and the adjacent lowlands of the Loire drainage, to the west (e.g., the Creuse) and to the north (e.g., the Cher). It is from these areas that comes most of the flint found (including not only end-products but also cores and debitage) in the UP sites of the Massif, which are located up to $300 \mathrm{~km}$ away from the corresponding sources (FéblotAugustins 2009; Fontana \& Chauvière 2009).

In the Dordogne drainage, lithic raw-material procurement and circulation patterns, combined with the geographic distribution of techno-stylistical idiosyncrasies in the choice or type of personal ornaments, indicate that, in the Solutrean Period, individual journeys would have involved distances no greater than 40 to $80 \mathrm{~km}$ (Castel et al. 2005; Map 3.19.2). From this evidence, the economic territories of individual bands can be modelled as circles with a radius between 20 and $40 \mathrm{~km}$, that is, ranging in size between $\sim$ I250 and $\sim 5000 \mathrm{sq} \mathrm{km}$. Assuming a band size of twenty-five people (Wobst 1974, I976), these areas translate into population densities of between 0.02 and 0.005 persons/sq km.

The seasonality data and the variation in the nature and intensity of the occupations further indicate that, besides the fugacious camps related to very specific extraction tasks, two functionally distinct kinds of sites were created in these territories: (a) residential camps corresponding to prolonged installations over more than one season, reflected in the richness of the deposits, the diversity of lithic raw-material provenances, the preponderance of tools related to domestic activities, and the high frequency of ornaments and decorated osseous implements (as well as, in some cases - for instance, the rock shelters of Fourneau du Diable and Le Placard - parietal art); (b) temporary camps, occupied for shorter periods of time, often in certain seasons only or predominantly, and where tool assemblages are mostly comprised of projectile points and other items related to the hunting, the processing of its products, or the production and maintenance of the associated weaponry (e.g., Combe Saunière, which is located at one-tothree days' walking distance from those residential sites).

The analysis, with similar criteria, of settlement-subsistence systems in an even more southerly region - the Portuguese
Estremadura - revealed a similar structural pattern (Zilhão 1997). The residential sites - open-air localities featuring lithic assemblages where all stages of the economy of stone tools can be recognised (procurement, production, use and discard) - are found along river valleys in the lowlands of the Tagus Basin and the littoral plain; on higher ground, cave sites were occupied logistically, as hunting stations (leaving behind artifact assemblages dominated by projectile points), or by small, all-ages groups (as denoted by the presence of children and adolescents among the Solutrean human remains from the cave site of Caldeirão; Trinkaus et al. 200I), perhaps individual families, that exploited the immediate environment, presumably in the summer, for its seasonal products (leaving behind assemblages combining imported hunting weaponry and large amounts of expedient, non-retouched, de facto flake tools made out of locally available non-flint rocks, namely quartzite). Rawmaterial circulation patterns, however, are suggestive of economic territories significantly smaller than to the north of the Pyrenees: in the range of $\sim 500 \mathrm{sq} \mathrm{km}$, that is, implying population densities of about 0.05 persons/sq $\mathrm{km}$.

This difference relates to a large extent to the kinds of resource packages provided by the environment. In Iberia, except for short periods and in restricted regions located in the foothills of the Pyrenees, reindeer were either entirely absent or economically unimportant. Complemented by horse and, in mountainous areas and in lowland but steep limestone country, the seasonal hunting of ibex (Straus 1987; Phoca-Cosmetatou 2004), the bulk of subsistence hunting fell upon red deer and aurochs, which are territorial animals. For hunter-gatherers exploiting terrestrial game of about the same size and in similar open-woodland environments, such as the Ona/Selk'nam guanaco hunters from Tierra del Fuego, the ethnographic evidence indicates territories and population densities of the same order of magnitude (García-Moro et al. 1997). A further feature of Iberian regions to the south of the Cantabro-Pyrenean mountain chain is that they harboured significant refugia of temperate and warm temperate trees, even through the longer and most adverse stadials of MIS 2, which means that diets could have included a significantly higher plant-food component. Direct evidence to that effect comes from (a) charred acorns recovered in the ongoing excavation of a sequence of well-preserved Solutrean hearths in the rock shelter of La Boja (Murcia, Spain; Zilhão et al. 2010c) and (b), in another meridional peninsula of Europe, from the starch grains of rushes (Typha sp.) and grasses (wild gramineae) found in grinding-stones excavated at the openair Gravettian site of Bilancino (Florence, Italy; Aranguren et al. 2007), attesting the production of flour (and some kind of bread) by UP hunter-gatherers as far back in time as 30,000 years ago. Recent finds from Pavlov (Czech Republic) and Kostenki (Russia) replicate the Bilancino evidence and suggest that such routine exploitation of plant foods may have characterised European UP economies at a Continent-wide level (Revedin et al. 2010).

Given the open nature of hunter-gatherer mating networks, territorial boundaries would have been rather blurred and traversed by routes of longer-distance exchange of exotic 


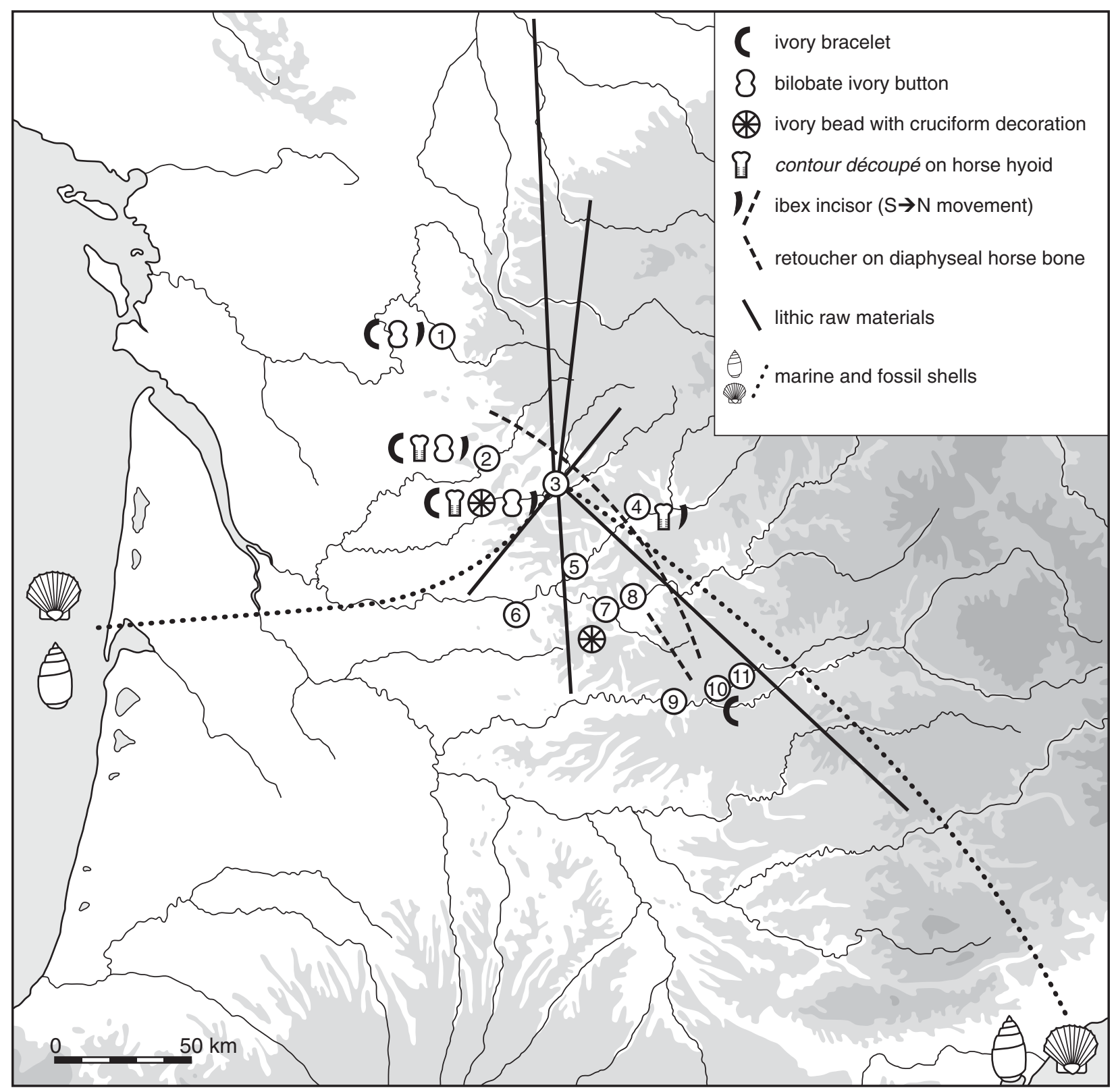

MAP 3.19.2. Regional distribution of personal ornaments in the Solutrean sites of the middle Dordogne Basin and adjacent regions: I. Le Placard; 2. Le Fourneau du Diable; 3. Combe Saunière; 4. Badegoule; 5. Laugerie-Haute; 6. Les Jamblancs; 7. Grotte XVI à Cénac; 8. Pech de la Boissière; 9. Cuzoul de Vers; Io. Les Peyrugues; II. Sainte-Eulalie. Also shown is the provenance of lithic raw materials and shells from Solutrean level IV of Combe-Saunière.

products, namely, the marine shells ubiquitously present in the UP ornament assemblages from the middle Dordogne Basin, which came from the shores of both the Atlantic and the Mediterranean, hundreds of kilometres away. Distances of more than $250 \mathrm{~km}$ were also travelled, often perpendicularly to natural circulation corridors, by some types of exotic flints consistently present in the UP sites of France (albeit, with the exception of the Massif Central, in low numbers and always in the form of end-products). These transport patterns suggest indirect procurement (e.g., through down-the-line exchange) and provide another indication of the geographical coverage of social interaction networks (Féblot-Augustins 2008). Much the same applies to other parts of Europe. For instance, the UP settlement sites associated with the open-air Palaeolithic rock art of the Côa Valley, in Northeast Portugal (see Chapter 3.20), yielded flint types from littoral or Iberian interior sources, more than $150 \mathrm{~km}$ away (Aubry et al. 2002). And, as indicated by the evidence from central and eastern Europe, such patterns are not restricted to the later parts of the period, nor do they reflect exceptional patterns determined by LGM-related factors of environmental stress; in fact, they can already be identified quite early on, in assemblages from the initial, Transitional Phase of the UP, namely, the Szeletian of Moravia and southern Poland. 
The evidence from western Europe is thus strongly suggestive of subsistence behaviours whose nature and variation essentially reflect the operation of an "eat what is there" (BarYosef 2004) principle. This can be seen not only in the differences between France and Iberia in the species that dominate UP faunal assemblages (reindeer and red deer, respectively), but also in the fact that, in France itself, red deer episodes also exist (Delpech et al. 2000; Delpech \& Texier 2007). A good example is level VII of the Flageolet I rock shelter, where red deer (found in association with other temperate forest elements, such as roe deer and wild boar) comprise as much as $70 \%$ of the number of identified specimens. This level contains Font-Robert points, an industrial phase well dated elsewhere in western Europe to $\sim 32,500 \mathrm{cal}$ вр (Jacobi et al. 2010), that is, the time of the GI 5 interstadial. Although reindeer are also present in the faunal assemblage ( $6 \%$, plummeting from an average of $66 \%$ in the underlying Aurignacian levels), the hunters shifted their preference to red deer at this time, presumably as a response to environmental changes that caused the relative abundance of both species in the landscape to be turned upside-down.

Western Europe has yielded most of the data and analyses relating to settlement and subsistence systems, but the "eat what is there" principle must also have worked in other, less intensively studied parts of the continent. And, indeed, in the Russian Plain, for instance, the large complex of sites at Kostenki-Borshchevo, on the middle Don, features faunal assemblages heavily dominated by horse in the Transitional and by mammoth and reindeer in the Early and Full phases of the UP. These changes correlate well with the environmental transformation that occurred through this interval of time from open pine and spruce forest to a treeless grassland and marshland where dwarf shrubs and trees survived only in protected niches along ravines and river valleys. A similar link between environment and hunting economy is apparent farther south, in the Pontic Steppe, where bison-kill sites (such as Amvrosievka, on the northern shores of the Sea of Azov) are a prominent feature of the archaeological landscape of the Full UP (Dolukhanov et al. 200I; Velichko \& Zelikson 2005).

Where the hunting of middle- and large-sized mammals is concerned, we can therefore conclude that the variation seen in the UP of Europe is determined above all by the availability of species and the structural properties of environments. When settlement-subsistence systems are considered in their totality, it is apparent that (a) hunted faunal assemblages reflect primarily the relative abundance of the targeted species; (b) the behaviour of those species (territorial or migratory, gregarious or solitary), and how it varies from season to season, determines whether or when intercept or encounter strategies are preferred; (c) the more intercept hunting is practiced, the more the hunters will tend to be organised along the lines of Binford's (1983) "collector" way of life (i.e., one that features mass-kill sites and the processing of the prey for deferred consumption at long-term residential localities); (d) conversely, a more "forager"-oriented way of life (i.e., one that features frequent changes of residence, as groups relocate to the kill instead of moving the kill to a more permanent settlement) characterises subsistence economies based on the encounter hunting of resources that are more scattered in both space and time; and (e) the degree of seasonal contrast in the overall availability of resources, a factor itself largely dictated by latitude, explains whether the deferment of consumption is limited in time (days or weeks) or involves preservation for long-term storage. In these respects, not much seems to have changed from the beginning to the end of the UP.

\section{Intensification, Demography and Innovation}

\section{Small prey}

It has been suggested that a diachronic trend across the MP and the UP can be discerned in the exploitation of small game and aquatic resources, with broad-spectrum economies once thought to be specific of the Mesolithic going back to the very beginning of the UP (Stiner et al. 2000; Stiner 200I). These notions find some support in a range of observations, namely, (a) the jump, from $20 \%$ to $30 \%$ in the MP to more than $80 \%$ throughout the entire duration of the UP, of the frequency of anthropically accumulated rabbit bones in faunal assemblages from Mediterranean Iberia (Aura et al. 2002a) and (b) the elevated values of ${ }^{15} \mathrm{~N}$, a stable isotope of nitrogen, seen 35,00040,000 years ago in human bone samples from Romania (Oase) and Russia (Kostenki), interpreted as an indication that over $50 \%$ of these individuals' dietary protein came from the consumption of freshwater fish (Richards 2009).

However, in southern Europe in general, and in Iberia in particular, small prey are a component of hunted faunas since the Lower Palaeolithic, as exemplified by Cova Bolomor (Valencia, Spain; Blasco 2008; Sanchis \& Fernández 2008; Blasco \& Fernández 2009): In basal level XVIIc of this site, whose age is in the range of half a million years, anthropically accumulated rabbits comprise $27.5 \%$ of the more than six thousand bone remains; the figure is $2 \mathrm{I} .8 \%$ in last-interglacial level IV, where tortoises comprise $20.2 \%$ of the remains, both taxa thus making up almost half of the faunal assemblage; and, in intermediate level VI, which dates to more than 130,000 years ago, diving ducks from the genus Aythia, hunted in nearby ponds and marshes and cooked and eaten at the site, comprise $36.4 \%$ of the fauna (the overall percentage of small prey in this level being, with the addition of rabbits, $83.6 \%$ ). Given this evidence, the parsimonious explanation for the regional UP pattern is environmental, as the difference with earlier periods resides in the fact that rabbits come to dominate this resource group almost exclusively. This rise to predominance has two causes: on one hand, the exceptionally arid climates that prevailed in the area during the stadials of the later part of MIS 3 and all of MIS 2, which greatly expanded the species' favoured habitats (d'Errico \& Sánchez-Goñi 2003; Sepulchre et al. 2007); on the other hand, the local extinction of the alternative 
small-prey animal, the tortoise, which, at this time, vanishes from anthropically accumulated faunal assemblages as much as from naturally accumulated ones (Morales \& Sanchis 2009). That the fluctuations in the number of rabbits found in archaeological faunas are to a large extent tethered to their relative abundance in the environment, not to economic intensification over time, is further indicated by the fact that, in regional faunal assemblages from the early Holocene (Mesolithic), the frequency of the taxon falls precipitously back to values of the same order of magnitude as in the MP (Aura et al. 2009).

The UP evidence also needs to be understood with issues of site function in mind, as shown by the contrasts between broadly contemporary occupations in two sites from the Portuguese Estremadura. In 25,80o-year-old level 2 of Lapa do Anecrial (Zilhão 1997; Almeida et al. 2006; Brugal 2006), a short-term sojourn by a small group (most likely, an overnight camp involving three persons) left behind a faunal assemblage comprising $100 \%$ rabbit bones ( 1516 , representing a minimum of fifteen individuals) that were in part consumed on site and in part skinned for their pelts. In slightly earlier, 27,200-year-old level EEI5 of the Lagar Velho rock shelter (Almeida et al. 2009), the remains distributed around two hearths also include some rabbits ( $12 \%$ ) but are mostly red deer (68\%), and the pattern of skeletal representation of the latter indicates on-site processing for the pelts and removal of the meat-bearing parts for consumption elsewhere.

The fact that these snapshots of activity were separated by sterile deposits from the remains of earlier and later visits enabled their preservation as individualised levels, but this is exceptional, as most archaeological deposits are palimpsests of successive occupations. Bearing this in mind, it is easy to see how sites characterised by repetitive uses of the Anecrial type might end up accumulating assemblages heavily dominated by rabbits, whereas sites whose use alternated with, or was mostly of the Lagar Velho EEI5 type, might end up accumulating red deer-dominated ones. Moreover, the largest rabbit assemblage in the UP of Mediterranean Spain, that from the 22,700-yearold levels XIII-XIV of Cova de les Cendres, yielded only $7 \mathrm{II} 4$ specimens ( $95 \%$ of the total), which, in light of the Anecrial evidence, (a) could have been accumulated in the framework of only a few very short episodes of human occupation and (b) given the small size of the package, would have yielded less meat than even a single one of the red deer that, with 2 II identified specimens, form the second-best represented taxon in the assemblage. In short, the Iberian evidence indicates that the variation seen in the consumption of small terrestrial prey is primarily related to species availability and site function parameters (Aura et al. 2002b), and much the same has been argued for the increase in the amount of leporid remains seen in sites of southern France towards the Final Phase of the regional UP (Cochard \& Brugal 2004; Jones 2007).

Where aquatic resources are concerned, the evidence from central and eastern Europe needs to be assessed against the fact that fish remains are virtually absent from the settlement sites of the regional Early UP which, even bearing in mind issues of differential preservation, is inconsistent with the dietary reconstructions derived from the isotope data. It remains possible that the contradiction is a simple reflection of the incompleteness of the archaeological record. Alternatively, it may represent instead a good illustration of the fact that the interpretation of high nitrogen values in human bones is not straightforward because (a) ${ }^{15} \mathrm{~N}$ is known to vary across time and space as a function of climate and vegetation, with corresponding implications for the cycling of nitrogen in soils and plants and, therefore, for environmental background values (Stevens et al. 2009), and (b) variation relating to as-yet poorly understood physiological and metabolic mechanisms may entail, for exactly the same dietary inputs, inter-individual differences in ${ }^{15} \mathrm{~N}$ values greater than the thresholds currently used to assess human trophic levels relative to other terrestrial animals (Hedges \& Reynard 2007). Thus, whether the idiosyncratic human isotopic evidence from the early phase of the eastern European UP stands indeed for an economically significant reliance on freshwater fish is at present an open issue.

In western Europe, ${ }^{15} \mathrm{~N}$ values as elevated as those obtained for Holocene humans whose diets have a significant, archaeologically documented aquatic component are only found in the Final Phase of the UP. One such example comes from Kendrick's Cave, in North Wales, dated to about $\mathrm{I}_{3}, 800$ years ago (Richards et al. 2005; Richards 2009). The implicated resource is inferred to be seal, and the dietary interpretation of the isotope evidence is in this case supported by the fact that, at this time, remains of marine fish and marine mammals do appear regularly at a number of coastal sites in Europe (e.g., the Cave of Nerja, in Spain; Aura et al. 2002b). Moreover, large numbers of freshwater fish are also found in contemporary inland sites. For instance, the Azilian levels of Pont d'Ambon (southern France), dated to about 12, I0o years ago, yielded about twenty-five thousand fish bones, their density in the deposits being as much as $400 / \mathrm{sq} \mathrm{m}$; the common dace and the eel were the targeted species, and the fishing took place in spring and summer (Le Gall \& Pannoux I994; Jones 2009). Similarly, the Epigravettian levels of Grotta di Pozzo (central Italy), dated to about I4,500 years ago, yielded about six thousand fish bones, their density in the deposits being as much as $2000 / \mathrm{sq} \mathrm{m}$; trout is the only species represented, and predominantly by cranial bones, which indicates seasonal fishing and processing (removal of the head and preservation of filleted portions) for deferred consumption elsewhere (Russ \& Jones 2009).

In southern and western Iberia and in Italy, the routine exploitation of marine resources (molluscs, seals, birds) is well documented in the MP (Stiner et al. 2000; Antunes 2000; Stringer et al. 2008; Zilhão et al. 2010a), but less so in the UP, although limpets are a common constituent of the UP sites of Cantabria (Straus 2005). This variation can be parsimoniously explained by glacio-eustatic sea-level change, implying, for any given archaeological locality, a shorter distance to the coeval coastline in MIS 3 than in MIS 2 times. Although the same factor conceivably accounts, at least in part, for the remains of seal and dolphin found in coastal sites of the Final Phase of the European UP, which coincides with deglaciation, neither varying distance to sea nor loss of coastal sites to postglacial submersion can explain why fish from inland rivers 
and lakes were routinely exploited at this time but not before. Thus, the evidence from Pont d'Ambon and Grotta di Pozzo can only be interpreted as an unprecedented economic development: in western Europe, beginning I4,500 years ago, hunter-gatherers systematically tapped a resource until then either ignored or exploited in mere anecdotical fashion.

It would be tempting to correlate this development with the major environmental upheaval associated with deglaciation, especially in France, whence reindeer migrate northward with the onset of GI I - the loss of such a key resource prompting the search for replacements down the trophic chain, namely, fish. Such an explanation, however, would overlook two facts: first, that nothing similar can be seen in the archaeological record of the last interglacial, even if the best evidence from this period comes from German lakeside settlements with excellent preservation, such as NeumarkNord (Wenzel 2007); second, that remains of anadramous fish (salmon and sea trout) become common in the archaeological record of Cantabria and Southwest France towards the middle of the Magdalenian (but not before, or at least not with a significant impact on nutrition, as suggested by the stable isotope results for the early Magdalenian female buried nineteen thousand years ago at Saint-Germain la Rivière, which indicate an exclusively terrestrial diet) (Straus et al. 2002; Drucker \& Henry-Gambier 2005). Since freshwater fishing has its roots in the exploitation of salmon runs in post-LGM times, when reindeer were still around and plentiful, the incorporation of continental riverine ecosystems in regular food-supply chains must reflect economic intensification, the ultimate cause of which can only have resided in a demographic spurt.

\section{Storage}

An entirely different line of evidence - settlement structure suggests that a similar demographic process may have been taking place at about the same time in eastern Europe. As with southern France, Italy and Iberia, the central part of the Russian Plain was never devoid of human settlement throughout the UP, not even during the LGM, shortly after which a remarkable type of feature appears for the first time, and ubiquitously, in the regional record: bone-filled pits, I $\mathrm{m}$ deep and $\mathrm{I} .5$ to $2.0 \mathrm{~m}$ in diameter, for which a short chronology, with all sites falling in the millennium centred around 17,500 years ago, seems to be the best reading of the dating evidence (Soffer I989; Soffer et al. I997; Iakovleva \& Djindjian 2005). These pits - dug during the seasonal thaw of the surficial part of the permafrost were natural refrigerators/freezers used to store processed carcasses (or, after consumption, to pile the bone leftovers for later use as fuel) in the framework of a settlement-subsistence system that involved summer acquisition, via the hunting of reindeer and mammoth, of the following winter's entire supply of meat.

The emergence of this storage economy - an adaptation for survival under the very long and harsh winters of the last glacial in a region located only about $200 \mathrm{~km}$ south of the Fennoscandinavian ice sheet - is associated with that of "village"-like agglomerations. The pits are distributed around dwellings built with mammoth bones, each covering an area of I6 to $35 \mathrm{sq} \mathrm{m}$, and, at sites such as Mezhirich, there is evidence that several were occupied at the same time, for as long as nine months, and that people returned periodically to them for the cold season. Their remaining in use for substantial amounts of time is in keeping with the substantial labour investment incorporated in the collection and transport of the construction material: dwelling I (Fig. 3.19.3), for instance, had foundations made with twenty-five buried crania (total weight: 2.5 tonnes, or 7.5 tonnes with the tusks), its exterior contour was reinforced with ninety-five mandibles, the roof had a chimney built with reindeer antlers through which escaped the smoke from a central hearth, and the whole was profusely decorated with geometric paintings in the visible parts (Bosinski I990). When seen in the light of the fact that the people of the preceding Kostenki-Avdeevo culture - mostly known from sites farther to the east in Russia but located in exactly the same latitudinal band of periglacial steppe - lacked such complex habitation features, the evidence for long-term sedentism coupled with large-scale storage implies economic intensification over time caused by significant population growth.

No equivalent evidence exists in western Europe, but the reason why, in Iberia and France, significant population growth may have occurred without generating intensification of similar visibility may well have resided in the outlet provided by the beginning of deglaciation, which opened up for recolonisation by humans all of central and northern Europe, deserted during the LGM (although a few controversial occurrences in Germany hint at occasional/seasonal forays or failed attempts at settlement; Terberger \& Street 2002). As shown by the evidence from both the shared Magdalenian material culture and the genetics of extant Europeans, such a recolonisation - which, I7,500 years ago, when mammoth dwellings appear in the Ukraine, had already reached areas of the upper Rhine Valley in both southern Germany and Switzerland seems indeed to have been carried out from the west, not from the east (Jochim et al. 1999; Gamble et al. 2006). Therefore, although expanding, the Magdalenian populations of western Europe may have been able to maintain more of the traditional ways of life because the growing numbers of humans in the landscape could be accommodated by the parallel growth in the amount of land available to them.

\section{Territoriality}

The only other point in time within the UP sequence of Europe where the overall patterning of the archaeological evidence is strongly suggestive of punctuated population growth is at the end of the Early Phase, about thirty-seven thousand years ago, with the first appearance of figurative art (see Chapter 3.20). The evidence consists of animal and human figurines sculpted in bone, ivory and slate found at sites in Austria and southern Germany (Conard 2003), plus animal and geometric parietal engravings from a number of rock shelters in Southwest France, as well as, if their dating is accurate, the famous animal paintings from the Cave 


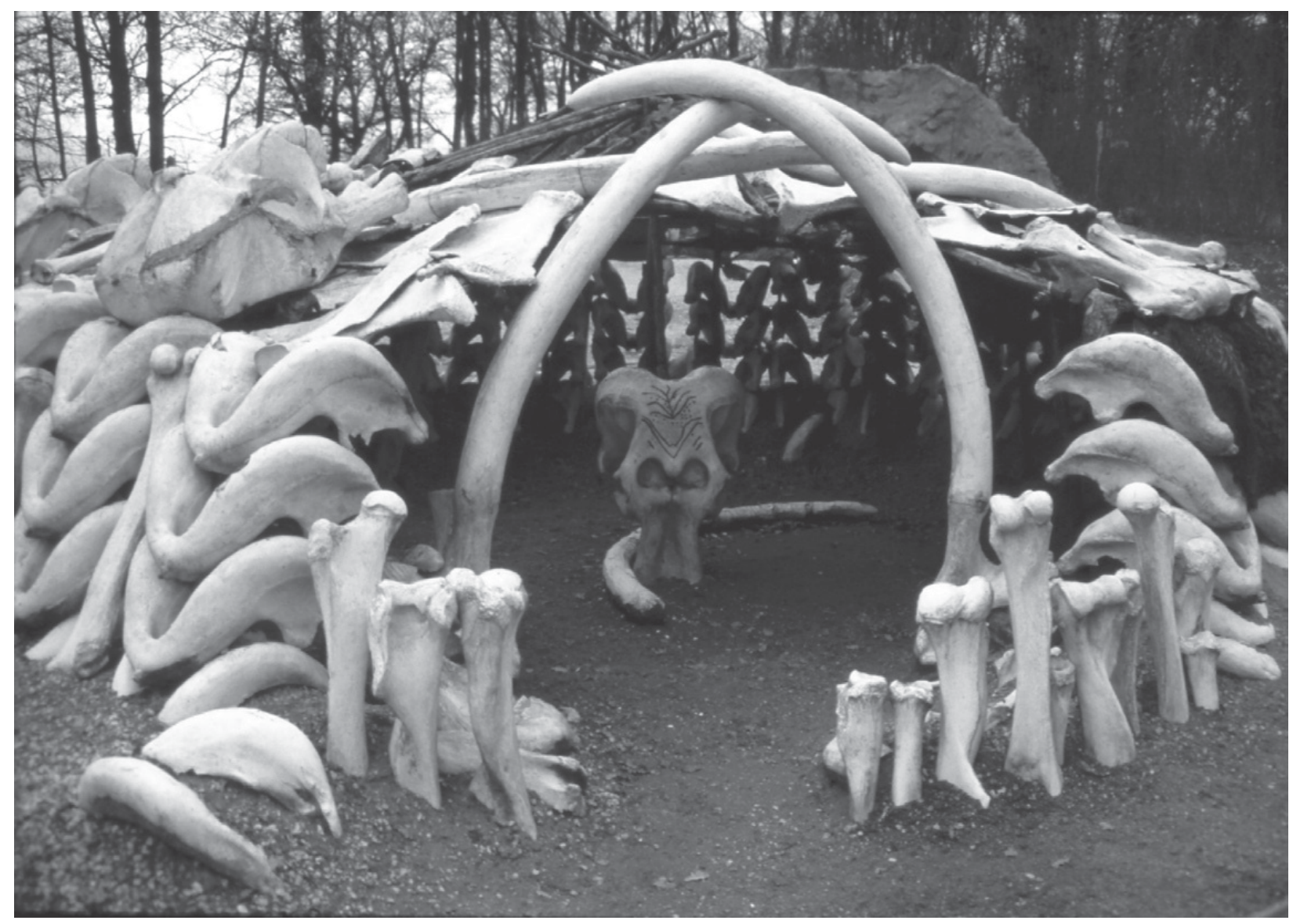

FIGURE 3.19.3. Mezhirich (Ukraine): reconstruction of dwelling I, in use $\sim$ I7,500 years ago. (Photo courtesy P. Bahn.)

of Chauvet, in the Rhône Valley (Valladas et al. 200I; Pettitt \& Pike 2007). Although cognitive models have been put forward to explain this development, they are inconsistent with the empirical data (Zilhão 2007), which are rather more suggestive of (a) those finds that so far have been made being but the tip of an iceberg extending across at least the entire areafrom Portugal to the Urals - covered by the associated archaeological culture (the Aurignacian II; see later in this chapter); (b) the evidence from caves and rock shelters being but a glimpse of a behaviour that impacted the entire landscape, as demonstrated by the slightly later open-air rock art sites from the Côa Valley, in Portugal (Zilhão et al. r997; Baptista 2009); and (c) this symbolic marking of territories representing in the first place, as among ethnographic hunter-gatherers, the staking of property claims over a given geographical space and its resources (Gamble I983; Gilman I984; Layton I992; Bahn \& Vertut 1997).

By contrast with its absence in the MP and earlier UP times, the emergence of art as a territorial marker must reflect the crossing of a population threshold above which increased intergroup competition required increased regulation of that competition by the putting in place of symbolic systems that encoded property rights - namely, via myths and religious beliefs relating the land to real or ideal ancestors of the people living off it. But, in contrast with post-LGM patterns, this Early UP demographic spurt does not seem to have been accompanied by readily apparent forms of economic intensification, as no evidence exists either for the adoption of long-term storage or for a broadening of the resource base. Therefore, at this time, the expansion in population numbers probably relates to improvements in the extractive efficiency of the human groups that were more of a technological rather than organisational nature, ones that enabled them to feed more people per unit of territory but without going down the food chain and without making significant changes to the mobile ways of life of yore.

In this sense, it must be significant that the Early UP growth came right after the period of experimentation with novel hunting weapons that characterises the Transitional Phase of the UP and eventually coalesced in the widespread Protoaurignacian technology. The common thread is the adoption of lithic production systems emphasising the obtaining of pointed blanks, lighter and more standardised than ever before, which most certainly underpins the search for the most effective way of arming weapons destined to be thrown rather than thrust (Teyssandier 2008). The success of the Protoaurignacian across a vast geographical expanse and a range of different environments is a reflection of the adaptive value of the solution, to which, with variations in fashion, UP hunter-gatherers would stick for the next twenty-five thousand years.

There is, however, a time lag between the "fixation" of the new technological system, about 4I,500 years ago, and the 
demographic spurt expressed in the emergence of figurative art, a few millennia later. At first glance, this lag would seem to counter the establishment of a causal link between the two processes, but, in all probability, it is an artifact of the operation of a contingent factor that got in the way of evolutionary logic: the huge volcanic explosion that occurred near Naples about 39,300 years ago and blanketed southern Italy, the Balkans and the Russian Plain with ash deposits (the so-called Campanian Ignimbrite, or CI tephra: Fedele et al. 2003, 2008), killing massive amounts of animal and plant life along the way. The "volcanic winter" effect of this eruption was enhanced by the very cold climate of GS 8/9, during which it occurred. At this time, which, moreover, coincided with the HS 4 iceberg stadial (Table 3.19.2), northern Europe witnessed a southward displacement of polar deserts. Combined, these environmental processes must have reduced by as much as 30\% the area of the continent available for settlement, causing a demographic crisis from which human populations necessarily took a while to recover (Zilhão 2006).

\section{Weaponry}

If technological progress explains the increased extractive efficiency underpinning population growth at the time of emergence of figurative art, could it be that it also explains the post-LGM spurt inferred from the Russian Plain evidence? Quite possibly, as this spurt is broadly synchronous with the first consistent archaeological evidence for the use of spearthrowers or atlatls, which comes from a group of Early Magdalenian sites in the Franco-Cantabrian region dated to about I8,6oo years ago (namely, El Mirón-González-Morales \& Straus 2009; however, a find made in Upper Solutrean level IV of Combe Saunière Cave, if not derived from the immediately overlying Early Magdalenian level III, may indicate a slightly earlier invention of the technology - Cattelain I989). The evidence consists of hooks carved out of antler, which, hafted onto longer handles, would serve to fasten the back end of a dart through the arm-flexing and arm-extension phases of the throw. Spearthrowers can propel a dart with enough precision, speed and force-at-impact to kill boar-sized prey at distances of up to $46 \mathrm{~m}$ (Hutchings \& Brüchert 1997), which is 2.5 times the maximum distance ( $18 \mathrm{~m}$, based on Australian Aboriginal evidence; Hughes 1998) from which a hand-cast spear or javelin can penetrate deep enough into the body of a similar-sized animal to cause death.

As the increase in the efficiency and safety of the hunt is very significant, one would expect the spearthrower-and-dart technology to spread very rapidly, so it is likely that (a) once invented, there would be strong selective pressure in favour of retaining the technology, at least until something better came along, and (b) the earliest archaeological proof of existence is indeed broadly contemporaneous with the time of invention. It has been claimed, however, that the innovation could in fact date to the beginning of the UP or even farther back in time to the Middle Stone Age (MSA) of southern Africa (Shea 2006). Such claims rest on analyses of the size, weight and thinness of ethnographic stone points showing that, on average, these parameters decrease, in order, from spear-point to dart-point and to arrow-point, with items in the range of the dart- or arrow-tip becoming widespread in the early UP of the Near East, and crescents from over 50,000-year-old African contexts being similar to projectile tips from more recent times. However, despite the differences in the average, there is a lot of overlap. For the best indicator, tip cross-sectional area, the ranges are, in sq mm, 8 to 146 for ethnographic arrowheads, 24 to 94 for ethnographic dart tips, 20 to $4 \mathrm{I} 3$ for MP points, and 5 to 150 for early UP points; and, in an example of points that were quite clearly designed for mounting on hand-cast spears (from the Vail Site of the Paleoindian Clovis culture of North America), the average is 107 ( $95 \%$ probability distribution: 53-I6r) (Shea 2006; Shea \& Sisk 2010).

This metric evidence is all the more inconclusive because spearthrower hooks are conspicuously absent from the extraordinarily rich array of tools made of bone, antler and ivory documented in Europe since the Aurignacian; if these raw materials were used for the manufacture of such hooks in the Magdalenian, why not, under similar climatic conditions, in similar treeless (or largely treeless) environments, and for the hunting of the same prey, were they never used for the same purpose prior to that time? The parsimonious reply is not that all spearthrower hooks were made of wood before the Magdalenian but that this powerful arm-extending machinery had not yet been invented. Rather than reflecting such an invention, the greater standardisation of earlier UP points when compared to those of the MP must therefore be seen as the endpoint of a process of gradual replacement of the heavier thrusting/throwing spear by the lighter stone point- or antler point-tipped javelin as the hunting weapon of choice (Villa \& Soriano 20I0; Villa et al. 2010). This conclusion is consistent with the physical anthropological evidence, which, despite the small sample sizes, (a) is suggestive of a greater emphasis on throwing during the Magdalenian and (b) fails to show any difference in this regard between the Early UP and the MP (Trinkaus 2008; Churchill \& Rhodes 2009).

It has also been speculated that such items as the barbedand-tanged or Parpallo points of the Upper Solutrean of Portugal and Mediterranean Spain provide evidence for a precocious invention of the bow-and-arrow (Tiffagom 2006). Many are indeed virtually identical to arrowheads from the regional Copper and Bronze Ages; the type, however, includes larger specimens, especially in Portugal and Andalucía, and the miniaturisation seen at the eponymous site is congruent with the small size of available raw-material nodules. For some (e.g., Wadley \& Mohapi 2008; Lombard \& Phillipson 2010; see also Chapter I.8), the invention could actually go back to over fifty thousand years ago, a time when microlithic crescents occur in consistent numbers in the Howiesons Poort MSA culture of southern Africa, from where the new technology would have spread to the rest of the world, hitchhiking on the dispersal of modern humans (and, perhaps, embodying the putative competitive edge underpinning their eventual worldwide prevalence). There are functional arguments derived from the analysis of those microliths themselves that counter this 
argument (Villa \& Soriano 2010; Villa et al. 2010). More importantly, were it to be valid, we would expect to find the bowand-arrow in the hunting arsenal of Australian Aboriginals, but we do not (Mulvaney \& Kamminga 1999). And we would also expect the technology to have entered the Americas with their first modern human settlers, but it did not; in fact, the bow-and-arrow is unknown in the Great Plains prior to two thousand years ago (Hughes 1998) and did not reach southern Patagonia and Tierra del Fuego until some five hundred years ago (Mena 1997).

Although the experimental evidence shows that, in terms of accuracy, killing power and approach to prey, the bowand-arrow is not necessarily better than the spearthrowerand-dart, the ethnographic data indicate that accurate shots can routinely be made from distances of up to $30 \mathrm{~m}, \mathrm{I} .5$ times that from which most spearthrower-propelled darts are used. In keeping with this, the archaeological evidence from North America shows that the bow-and-arrow was indeed an advantageous weapon system, as, once invented, it replaced very rapidly - within half a millennium at most the functionally equivalent spearthrower-and-dart, as well as the javelin, with only the thrusting spear persisting alongside as a complementary weapon used at close range in warfare or to finish off wounded prey. Besides the greater effective distance, the bow-and-arrow has other advantages, namely, the rapidity of repeated fire and the fact that it can be shot from a variety of positions, making it a more performing weapon in wooded environments (Hutchings \& Brüchert I997; Hughes 1998).

This review of the evidence supports two conclusions. Firstly, when the relevant size parameters of point assemblages encompass the range of arrowheads, dart-tips and javelin points (as happens with the Parpallò points of the Iberian Solutrean), the parsimonious interpretation is not that the three weapon systems coexisted but that the points in question were all used to arm either javelins or, after the spearthrower's invention, darts. Secondly, the first invention of the bow-and-arrow must have been a recent event, with the earliest direct proof being very close in time to that event indeed. At present, such proof consists of the $\sim$ II, 6oo-year-old ensemble of one hundred stone-tipped, pinewood foreshafts and arrow shafts bearing the characteristic proximal nock found at the Ahrensburgian site of Stellmoor, in Germany (Bergman I993; Bratlund I996), where the bow-and-arrow was used to hunt reindeer in the tundra environment of the Younger Dryas. Thus, although the fact that it is principally advantageous in forest hunting may well explain why the bow-and-arrow (a) never diffused into Australia and (b) replaced the spearthrower-and-dart very rapidly in both the North America of the Late Holocene and the Europe of the Terminal Ice Age, the evidence from Stellmoor also shows that its eventual success cannot be simplistically linked purely to the late glacial expansion of woodlands.

Ahrensburgian hunters also benefited from the help of dogs, whose domestication, despite claims that it may have been accomplished in the Aurignacian (Germonpré et al. 2009), is not securely documented until $\sim$ I3,500 years ago, the time of a human-and-dog burial from Bonn-Oberkassel, in Germany
(Street et al. 2006). Incidentally, this is the same age obtained for the oldest Near Eastern dog, that from the Natufian site of Ein Mallaha (Israel), which, as in the German case, was found in a human burial context - the only kind of context that, given the overlap in size and morphology between early dogs and wolves, unambiguously implies domestication (Davis I987; Davis \& Valla 1978). These are the oldest fossil dogs currently known (Detry \& Cardoso 2010), and whether their domestication was functionally integrated with the invention of the bowand-arrow or simply broadly coincidental in time remains an open issue; however, both clearly occurred in a hunter-gatherer environment and represent the last of the major technological innovations that the Ice Age peoples of western Eurasia bequeathed to Holocene humanity.

\section{Division of Labour}

The skeletal studies of throwing behaviour discussed in this chapter found no evidence for inter sex differences in the Magdalenian sample, which raises the possibility that, at least by this time, if not before, women may also have been involved in hunting activities. If so, the gains in extractive efficiency derived from the invention of the spearthrower could have been twofold as, by increasing the minimum approachdistance to prey, the new technology (a) increased the number of opportunities to take an accurate shot and, therefore, the effective number of kills that could be achieved per unit of time/energy spent in the pursuit of the game, and (b) increased the security of the hunt, allowing the incorporation of females without jeopardising the reproductive potential of the group, thereby multiplying the workforce involved in the task and, therefore, its yield. However, this incorporation does not seem to have taken place across the board, as suggested by a study of upper-limb enthesopathies, which are lesions caused by activity-related stress at muscle attachment sites (Villotte et al. 20I0). This study confirmed a higher level of upper-limb activity in the Magdalenian relative to the earlier UP and also found that, although none of the observed lesions could be specifically attributed to atlatl use, some were clearly related to the hand-throwing of spears - in all cases, however, the affected individuals were male, not female. This pattern suggests that, alongside the spearthrower-and-dart, javelins continued to play an important role in Magdalenian subsistence hunting and also that these more risky hunts were predominantly, if not exclusively, a male job.

If representative, the skeletal evidence implies that the elements of a sexual division of labour seen in the Magdalenian could also have existed among the javelin hunters of the earlier UP (and, by the same token, among the spear hunters of the preceding MP too). This inference is in good agreement with material-culture patterns. In cold temperate or subarctic environments, the making of tailored, weather-resistant clothing and well-insulated artificial shelters are high-skill and female-associated tasks. The presence in the archaeological record of the kinds of tools that they require (namely, bone needles and awls) can therefore be taken as a proxy for females having taken on the role of technology specialists 
(Kuhn \& Stiner 2006). The earliest-known eyed needles come from the pre-LGM Gravettian-like cultures of eastern Europe, with finds from Kostenki I5 dating to over thirty thousand years ago (Hoffecker 2005), but several contexts of the initial, Transitional Phase of the UP have yielded significant numbers of awls in association with consistent functional evidence. The best example comes from the Châtelperronian levels of the Grotte du Renne (Burgundy, France), with experimental replication indicating that the fifty awls recovered therein were subjected to a very intensive use - a minimum of twenty thousand perforations on $2.5 \mathrm{~mm}$-thick leather, with many, given their fineness, having probably been used on less-resistant materials, such as furs, bird hides or intestines (d'Errico et al. 2003 b). This evidence implies the making of tailored clothes and also (if, in subarctic environments, such tasks are primarily female ones) the existence of an institutionalised sexual division of labour in the Neanderthal societies of the earliest UP.

\section{Social Geography and Culture}

\section{The Transitional Phase}

The earliest cultures of the European UP form a regionally diverse array of lithic technological systems that already fit most, if not all, aspects of the period's definition (Fig. 3.19.4). The Châtelperronian of the Franco-Cantabrian region features volumetric blade production oriented towards the production of blanks for curve-backed Châtelperron points and knives. The Uluzzian of Italy and Greece is a flake-based industry that also features some production of non-Levallois blade blanks but is mostly defined by the manufacture of geometric microliths, namely, lunates; as in the Châtelperronian, this lithic inventory is complemented by bone awls (d'Errico et al. 2012). The Bachokirian of Bulgaria is made on Levallois blade blanks but the preponderance of end-scrapers gives it an undeniable UP cachet. The Bohunician of Moravia and southern Poland is characterised by the production of morphologically Levallois points obtained by non-Levallois methods and is associated from the beginning with bifacial foliate point types (Blattspitzen) that, in different parts of central and northern Europe, characterise somewhat later contexts for which the terms Szeletian, in Hungary, and Altmühlian, in Germany, have been coined; eventually, these assemblages developed into unifacial bladepoint industries, such as the Lincombian of England and the Jerzmanovician of eastern Germany and Poland. In Ukraine and Russia, the initial phase of the UP is represented by the Streletskayan, which extends from the shores of the Black Sea to the middle Don River and combines Blattspitzen-like foliates with backed, trapezoidal microliths and bone tubes and handles.

The problems inherent in the use of radiocarbon to date archaeological contexts so close in age to the limit of applicability of the method make it difficult to extract a coherent chronometric pattern from the data (Zilhão \& d'Errico I999;
Higham et al. 2006a). However, when strict quality-control criteria are used in combination with the evidence provided by alternative methods (such as Thermoluminescence or TL dating) and by independent, Continent-wide stratigraphic markers (such as the CI tephra), a rather clear picture emerges (Zilhão 2006, 2007) - one where these transitional assemblages first appear as early as about forty-eight thousand years ago, the age obtained for the Bohunician, by both TL and radiocarbon, at the eponymous Czech site of Brno-Bohunice and other nearby localities (Richter et al. 2009).

As a broad similarity exists between the Bohunician and the Ehmiran of the Near East, and both emerge at about the same time, some scholars have suggested that the former is in fact but a westward extension of the latter, and gone on to suggest that the pattern stands for the archaeological signature of a pioneer wave of modern human immigration (Svoboda \& Bar-Yosef 2003). However, whether the Ehmiran itself was made by modern humans remains a moot point; given the lack of associated fossils, it could just as well have been made by Neanderthals, and all the more so given the terminus post quem for the latter's disappearance from the Near East provided by the TL date (about fifty-three thousand years ago) obtained for level BI of Amud (Israel), which contained the burial of a Neanderthal adult (Valladas et al. 1999; Rink et al. 200I; see Chapter 3.I). Both cultures have roots in the preceding MP (as seen, for the core area of the Bohunician, in the technological transition to the UP documented across the different levels of the Piekary IIa site, in southern Poland; Sitlivy et al. 2008), and their resemblance probably reflects, therefore, convergent, independent invention. Alternatively, it could represent rapid diffusion of an innovation across interaction networks - in this case, the fixation of stone-tipped javelins in the role of primary hunting weapons, which may have occurred as a common response to the environmental challenges raised by the setting in of the rather long period of predominantly interstadial conditions that followed the onset of GI I2. Where the Bohunician is concerned, the impression of regional continuity is further strengthened by the fact that coeval human skeletal remains surrounding its core area in all directions, whether found in stratigraphic association with archaeological contexts of the earliest UP or directly dated to its time range, are exclusively of Neanderthals (e.g., Spy in Belgium, Neanderthal in Germany, El Sidrón in northern Spain, or Vindija in Croatia; Higham et al. 2006b; Schmitz 2006; Semal et al. 2009; Zilhão 2009; Torres et al. 2010).

As with the point types of the pre-Magdalenian UP, those of the initial stages of the Transitional Phase are functionally equivalent variants of the same concept - the stone tip produced for mounting on a hand-cast projectile. The observed interassemblage variability in point types and other aspects of stone-tool technology must be seen, therefore, as (a) essentially neutral from an adaptive perspective and (b) reflecting either cultural change over time or, when synchronic, differences at the "ethnic" or "culture area" level. This inference is supported by the evidence from the associated ornaments. In the Uluzzian, they are mostly Dentalium beads, in the Châtelperronian they are mostly perforated animal teeth, and 

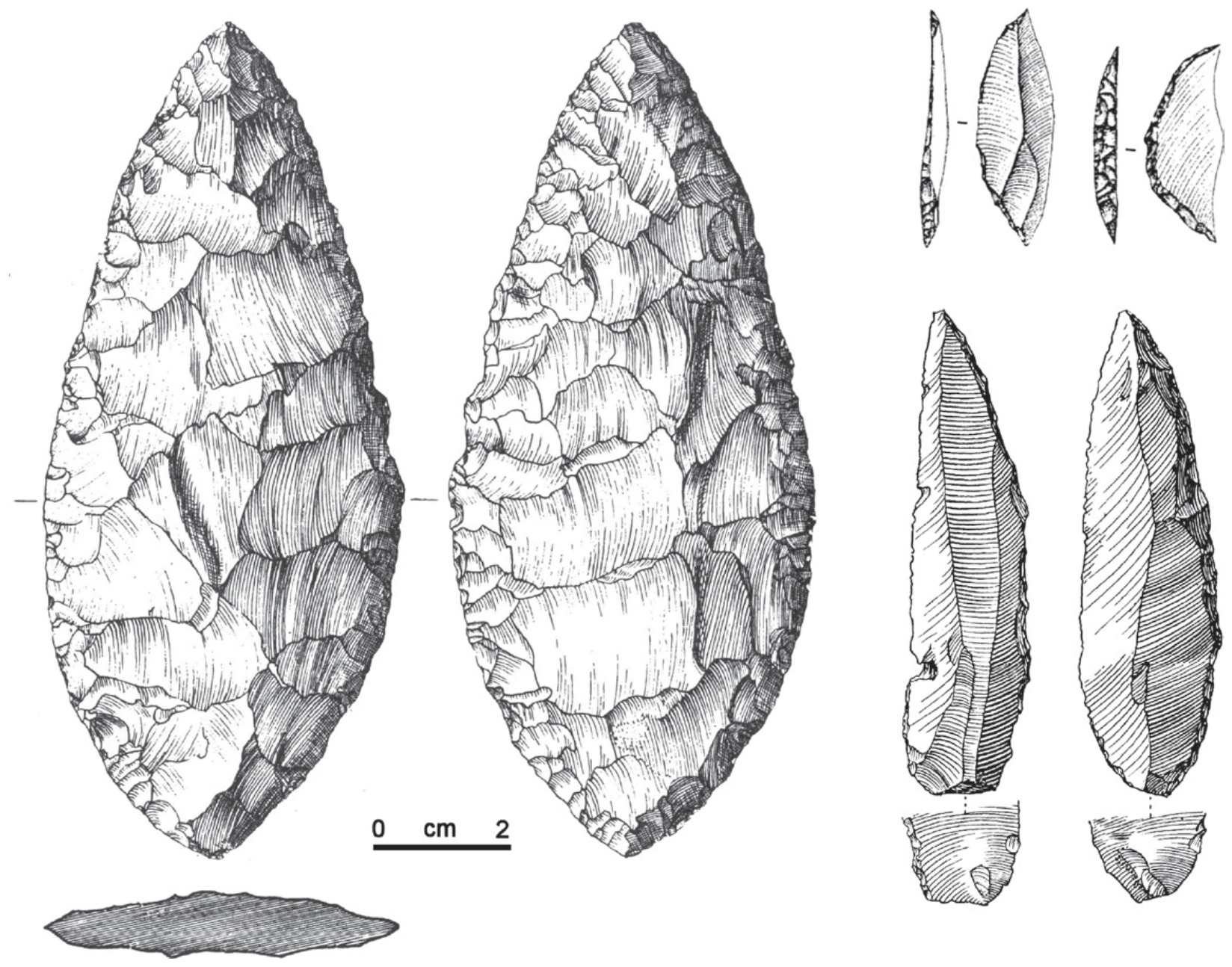

FIgUrE 3.I9.4. Stone tools of the Transitional Phase. Left: Altmühlian Blattspitze (from Horizon 2 of the Ilsenhöhle, Ranis, Germany). Top-right: Uluzzian lunates (from level EI-II of Grotta del Cavallo, Italy). Bottom-right: Châtelperron points (from the Grotte des Fées at Châtelperron, France).

in Belgium and Germany the few examples that can be attributed to this time range are ivory discs and rings (Zilhão 2007).

The association of these items with such Neanderthalrelated techno-complexes has always been a major obstacle to "Human Revolution" views of the UP, in the framework of which, therefore, it was commonplace to argue (e.g., most recently Mellars 2010) that the ornaments would correspond in fact to intrusions from overlying modern-humanassociated deposits, namely, Aurignacian ones. The key site in these debates is the Grotte du Renne (Map 3.I9.I), where sample contamination issues have hindered the dating of the Châtelperronian levels (VIII-X). In fact, until recently, only two out of the seventeen results available were consistent with the stratigraphic position of the samples - underlying a Protoaurignacian level (VII) and thereby older than 4I,500 years ago (Zilhão \& d'Errico 2003). However, new dating work by Higham et al. (2010), who used more stringent protocols for the pretreatment of bone samples, considerably ameliorated this panorama, as only eight out of their twentyone results came out younger than expected, and the remaining anomalies are easily explained as a byproduct of ever more residual but persistent contamination issues. Even if, for the sake of argument, one accepts that they reflect stratigraphic disturbance instead, the implication for the assemblage of thirty-six personal ornaments from levels VIII-X would be that, although a similar percentage $(38 \%)$ is conceivably displaced, most are in situ - that is, genuinely associated with both the Châtelperronian stone tools and the Neanderthal dental and cranial remains found therein. Moreover, the overall vertical and horizontal find distribution patterns make it archaeologically impossible for the items of personal ornamentation in level $X$ (twenty-five) to be intrusive from the Protoaurignacian, as level VII, the putative source, (a) contained a much smaller amount (only four) and (b) contributed to the underlying deposits not a single one of its hundreds of diagnostic stone tools (e.g., Dufour bladelets). These simple facts allow us confidently to reject the hypothesis that the ornaments found in the Chattelperronian levels of the Grotte du Renne reflect massive intrusion from above ( $c f$. Zilhão $201 \mathrm{I}$ for a detailed discussion).

The panorama of a Europe that is homogeneous from a human palaeontological perspective but diverse from an 

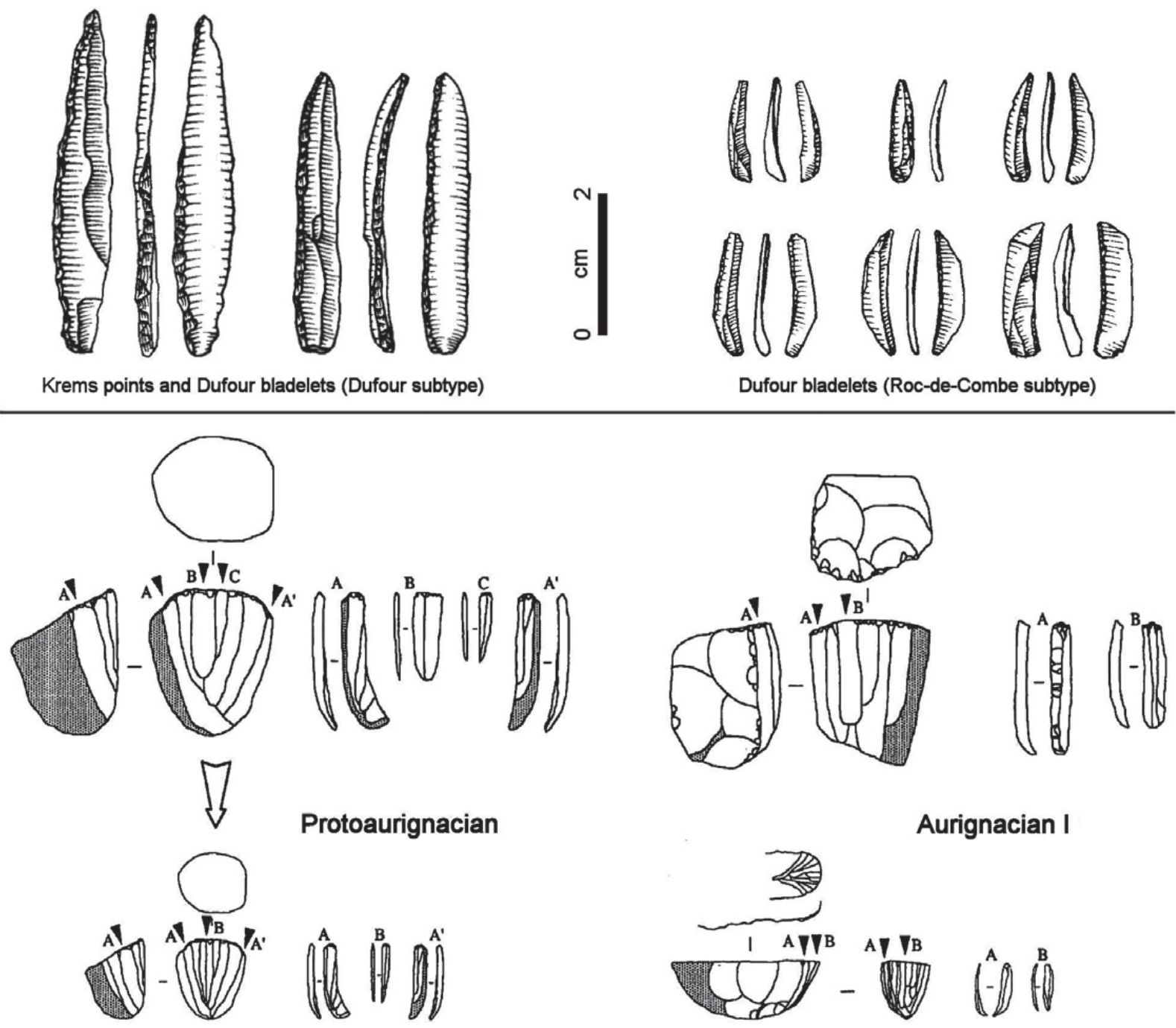

FIGURE 3.I9.5. Protoaurignacian and Aurignacian stone tool production. Top: retouched bladelets; the Krems point and the subtype Dufour are characteristic of the Protoaurignacian, the subtype Roc-de-Combe of the Aurignacian II. Bottom: blade/ bladelet production schemes - the chain of reduction is continuous in the Protoaurignacian, discontinuous in the Aurignacian I.

archaeological perspective changes $\sim 4 \mathrm{I}, 500$ years ago with the irruption of the Protoaurignacian. This industry is characterised by long, slender Krems micropoints and Dufour bladelets of the Dufour subtype (Demars \& Laurent 1989), the blanks for which are extracted from unidirectional blade cores in the framework of a single, continuous reduction sequence (Bon 2002; Bordes 2006; Fig. 3.I9.5). The emphasis on standardised bladelets mounted with resins on bone/antler or wood points axially, as point-tips, or laterally, as tissue-shearing components that enhanced the bleeding effect of the wounds inflicted by the penetration of the projectile in the prey - is unprecedented in Europe (where, however, the lunates of the Uluzzian may represent a functionally equivalent solution obtained with a different technology). Yet, such an emphasis is matched in the broadly coeval Early Ahmarian assemblages of the Near East (see Chapter 3.3), with which the Protoaurignacian also shares most of its personal ornaments - beads made of marine shells of Nassarius and other taxa of roughly the same small size and basket shape.
By its stark contrast to the cultural patterning of immediately preceding times, the emergence of the Protoaurignacian represents a clear discontinuity in the European archaeological record, one that affects the realms of both basic technology and symbolic culture. Moreover, this discontinuity coincides with the first appearance in Europe of fossils that, despite the presence of archaic, Neanderthal traits, are overall modern in anatomy - those from Oase. In this context, it is difficult to object to the notion that the Protoaurignacian represents an archaeological signature for the immigration of modern humans. Given the palaeontological and genetic evidence for complex population dynamics at the time of contact, it remains possible, however, that the spread of the techno-complex is underpinned by a variety of demic scenarios. From Kozarnika (Bulgaria) and Tincova (Romania) to Fumane (Italy), Isturitz (French Basque Country) and L'Arbreda (northern Catalonia), it probably stands indeed for a wave of demic dispersals ultimately originating in the Near East and featuring variable interbreeding with, and eventual absorption of, the local Neanderthals - explaining the 
survival into the Protoaurignacian of these regions of ornament types (namely, perforated animal teeth) that are characteristic of the Bachokirian and the Châtelperronian but unknown in the Early Ahmarian (Zilhão 2007). However, the absence of shell beads from both the Protoaurignacian and the succeeding Aurignacian of Cantabrian Spain may indicate, rather than population intrusion, local adoption of a technological innovation perceived to be advantageous once it became available for borrowing in a nearby region; in short, that, along the western shores of the Bay of Biscay, the Protoaurignacian may have been made by Neanderthal groups that, except for aspects of their hunting technology, remained largely unaffected by genetic and cultural exchange with modern groups from adjacent areas to the east.

Although whoever made the Protoaurignacian of the Cantabrian strip remains an open issue, elsewhere in Iberia the pattern is rather clear and is one of persistence of the MP - associated with diagnostic Neanderthal remains at the key site of Sima de las Palomas (Murcia, Spain) - until about thirty-seven thousand years ago (Walker et al. 2008; Zilhão et al. 20I0a, 2010b). A similar, but shorter-lived persistence into the time range of the Protoaurignacian (but not beyond) of both the Neanderthals and the regionally associated material culture - in this case, the Lincombian/Jerzmanovician - is indicated by the dating of a few sites in Britain (Jacobi 2007) and the age of about forty-one thousand years ago or less obtained for directly dated fossils from Spy (Semal et al. 2009). Although reasoning by stratigraphic association is precluded at this site by the inadequate methods used in its early Igth-century excavation, the dating is consistent with three observations: firstly, that the northernmost occurrence of the Protoaurignacian in western Europe (level VII of the Grotte du Renne) lies in Burgundy, some 500 kilometres to the south; secondly, that Jerzmanovician-like blade-points presumably associated with the dated Neanderthals exist in the Spy collections; thirdly, that the presence in said collections of split-based bone points typical of the earlier Aurignacian (see later in this chapter) sets an upper limit of $\sim 40,300$ years ago for the age of the site's bladepoint occupation.

In the Russian Plain, the Spitsynian from level II of Kostenki 17 , so far an isolated occurrence but lacking in bifacial foliates and featuring a developed blade/bladelet, fully UP technology that sets it apart from the Streletskayan (Sinitsyn 2003), probably represents, given these traits and its stratigraphic position under a CI tephra deposit (Anikovich et al. 2007), an intrusion into the regional archaeological record akin to the Protoaurignacian of regions to the west. In this case, a clear connection with cultural developments in the Near East is apparent in the fact that a perforated Columbella shell, modern representatives of which are today confined to the Mediterranean Basin, more than $700 \mathrm{~km}$ away, was recovered in level IVb of Kostenki I4; the associated stone-tool assemblage, although of uncertain cultural affiliation, is unambiguously UP and dates to the time range of the Protoaurignacian. In parts of what is now the Black Sea area, however, the MP seems to have persisted alongside the Transitional UP, as documented by the characteristic assemblage of Kiik-Koba type found in level B of
Buran Kaya III, where it overlies Streletskayan level C (Marks \& Monigal 2004); but, because level B is in turn overlain by UP level 20, for which an age of about thirty-nine thousand years ago, about the same as that of the earliest UP of the northern Caucasus (Adler et al. 2006), has been obtained, this persistence was shorter-lived than in Iberia. As the Crimean sites are for the most part temporary mountain camps (Patou-Mathis 2009), the Buran Kaya III pattern probably reflects alternating uses of the region by Neanderthal groups of distinct cultural affiliations coming into it for logistical purposes from both the North (for the Streletskayan groups) and the East (for the MP groups).

In Iberia, the end of the persistence pattern coincides, in time, with that of a long period of predominantly interstadial conditions (from the beginning of GI 8 to the end of GI 7) during which, in space, a significant gradient in forest cover was created, or enhanced, at the latitudinal boundary between the mutually exclusive distributions of the late MP and the Protoaurignacian (see earlier in this chapter). This socioecological "Ebro Frontier" pattern must therefore reflect a longlasting separation between populations with two very different adaptive systems. A modern analogue is the durable boundary that, in the Canadian Arctic, east of the Mackenzie River, separated the tundra "Eskimo" from the forest "Indians", with occupancy of segregated territories and little or no biological or cultural interaction taking place as a result of both sides deliberately adopting a contact-avoidance strategy - a pattern that is documented from the time of European colonisation until as far as back as the archaeological and ethnohistorical records reach (Graburn 1979). In the Iberian case, while people living north of the "frontier" continued at this time to thrive as steppe-tundra hunter-gatherers, even across interstadial oscillations whose amplitude was insufficient to significantly change their environments, those located to the south of the frontier would have been impacted by the vast expansion of woodlands, leading to a decrease in the biomass of herbivores and, in response, to a concentration of settlement in ecotonal areas rich in alternative resources. Empirically, this can be seen in the location of the MP sites from south of the frontier that contain occupations dated to the period of its duration, which do suggest a littoral-oriented settlement. (New excavation and dating work carried out at Figueira Brava in 2010-13 has shown that the deposits rich in marine foods are of late MIS 5 , not late MIS 3 , age.)

\section{The Early Phase}

No later than about forty thousand years ago, a new technocomplex appears in the European UP record - the Aurignacian (Fig. 3.I9.5). The emphasis is now on the mass production of blades, with cores being abandoned when they are no longer fit for purpose, and bladelets being extracted from small nodules or thick flakes recycled from the initial phase of decortication and preparation of the blade production sequence. This strategy produces characteristic types of bladelet cores. In stratified sites, such bladelet cores change through time in consistent fashion and in tandem with both the blanks 

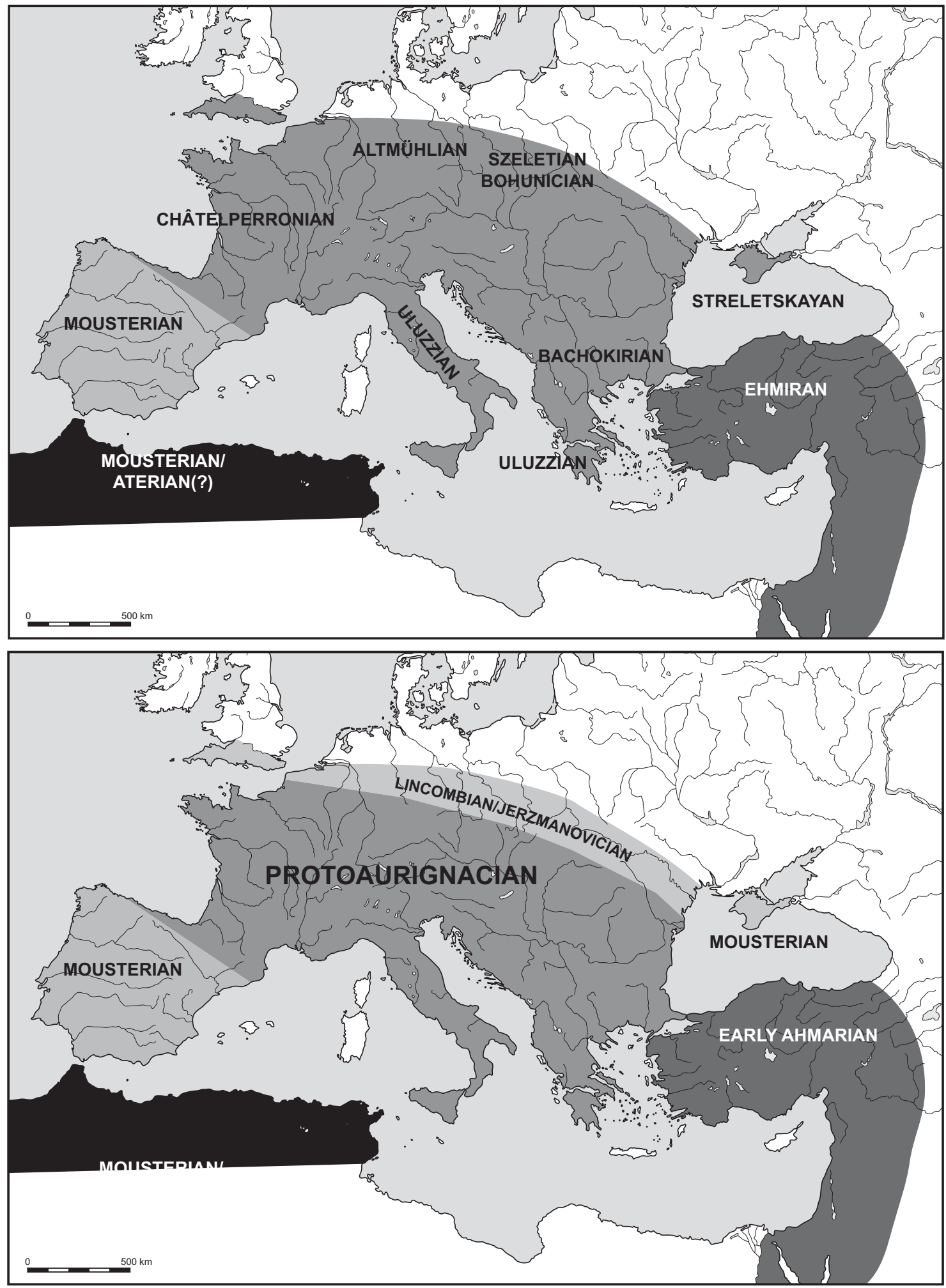

MAP 3.19.3A. Culture geography of the Greater Mediterranean during the Transitional and Early phases of the Upper Palaeolithic. Before (top) and after (bottom) 4I,500 years ago. Note the initial persistence of Neanderthal-associated MP (Mousterian) and UP (Lincombian/Jerzmanovician) Palaeolithic cultures to the north and south of the Protoaurignacian intrusion, and the eventual disappearance of the "Ebro Frontier" as a result of the spread into Iberia of the Aurignacian II. (After Zilhão 200I, with modifications that account for corrections in the calibrated timescale arising from the use of the INTCALo9 calibration curve.) 

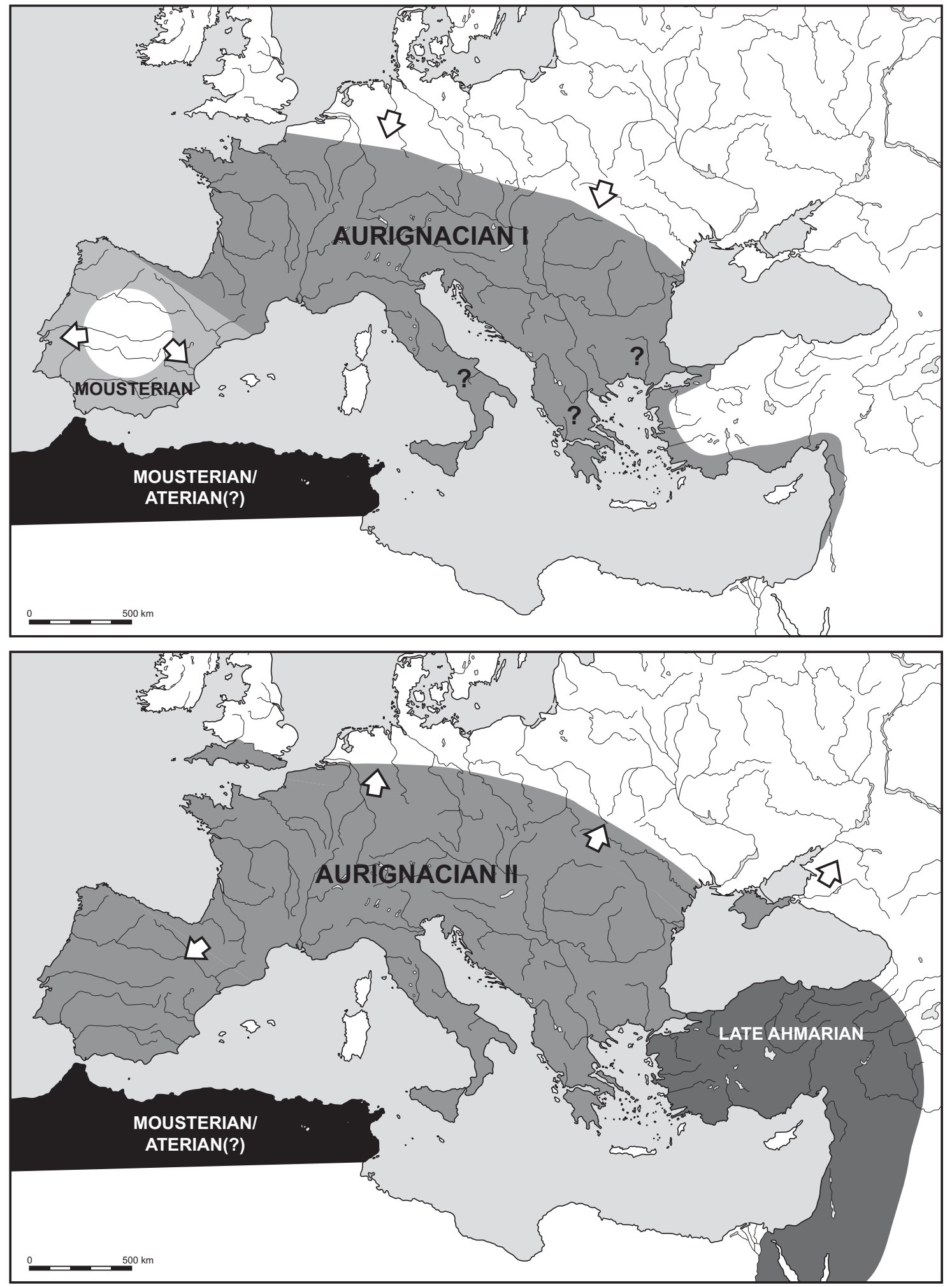

MAP 3.I9.3 B. Culture geography of the Greater Mediterranean during the Transitional and Early phases of the Upper Palaeolithic. Top: during the $\sim$ 40,000-37,000 interval, which encompasses Heinrich Stadial 4 and the volcanic explosion that formed the so-called Campanian Ignimbrite tephra. Bottom: after 37,000 years ago. Note the initial persistence of Neanderthal-associated MP (Mousterian) and UP (Lincombian/Jerzmanovician) Palaeolithic cultures to the north and south of the Protoaurignacian intrusion, and the eventual disappearance of the "Ebro Frontier" as a result of the spread into Iberia of the Aurignacian II. (After Zilhão 200I, 20II, with modifications that account for corrections in the calibrated time scale arising from the use of the INTCALog calibration curve.) 
they produce and the mode of retouch used to shape them. This means that the Aurignacian can be subdivided into (a) an Aurignacian I, defined by cores of the "carinated scraper" type (in the initial stages of lithic typology studies, these cores were mistaken for actual tools, hence their misleading designations, which simply reflect the history of the subject), from which slightly curved and naturally pointed bladelet blanks were extracted and often used with no additional retouch; (b) an Aurignacian II, defined by cores of the "nosed scraper" type, which produce very small and twisted blanks, marginally retouched (the so-called Dufour bladelets of the Roc-de-Combe subtype; Demars \& Laurent 1989); and (c) the Aurignacian III-IV, defined by cores of the "carinated burin" type, which produce long, robust, straight bladelet blanks retouched into so-called Font-Yves and Pego do Diabo micropoints (Pesesse 20I0; Zilhão et al. 20Iob). Projectile tips made of bone and antler were also used throughout, and these came, for the first time, in well-defined categories with widespread geographical distribution and a clear chronology, confirmed by direct dating of characteristic specimens (Rabeder \& Pohar 2004; Bolus \& Conard 2006; Szmidt et al. 2010): the split-based type, exclusive to the Aurignacian I, and the massive-based type of overall lozenge morphology, which is found in the Aurignacian II and III-IV.

Geographically (Maps 3.19.3a and 3.193b), the extreme outposts of the Aurignacian I are, in the west, the Asturian rock shelter of La Viña and, in the east, the caves of Kebara and Hayonim, in northern Israel, that is, about the same extension as the Protoaurignacian, and the same is broadly true latitudewise. There is, however, one important difference, and that is the lack of any Aurignacian I finds in southern Italy, in the Balkans and east of Hungary. By comparison with the distribution of the preceding Protoaurignacian, this void coincides almost exactly with the area that was ash-blanketed by the CI volcanic event. If a causal connection exists and the absence of archaeological occurrences reflects a genuine absence of human settlement at this time, the flow of information and personnel between western Europe and the Near East would have been interrupted, which is seemingly contradicted by the Israeli sites. Since, on current evidence, the Naples volcanic eruption postdates by a few centuries the earliest dates for the Aurignacian I, including those obtained for the corresponding level (IIf) of Kebara (Bar-Yosef et al I996; Zilhão 2007), a possible solution for the conundrum is the following: (a) by the time of emergence of the Aurignacian I, long-distance diffusion networks uniting Iberia to western Asia were still operative; (b) initially, central, eastern and southeastern Europe also participated in the process; (c) due to vast expanses of these regions having become uninhabitable shortly thereafter, as a result of the volcanic catastrophe, the number of sites left behind at this time was too small to fall above the threshold of archaeological visibility; and (d) the break with the Near East explains why its culture-stratigraphic sequence diverged from the European one after the split-based bone point plus "carinated scraper" episode (a so-called Late Ahmarian, which does not match the industrial definitions of the Aurignacian II and III-IV of Europe, is recognised in the regional sequence after the Aurignacian I; Bar-Yosef \& Belfer-Cohen 20I0; see Chapter 3.3).

Another difference with the geography of the Transitional Phase is that central and northern Europe, which were never directly affected by the ash fall, seem to have become devoid of human settlement at this time too. This probably reflects the southward extension of the polar deserts that occurred during the severely cold GS 8/9 stadial and the attendant local extinction of human populations, in this case the makers of the Lincombian-Jerzmanovician Culture, that is, the last of the northern Neanderthals. In Iberia, this climatic event led to major aridification in the central Meseta and the eastern and southeastern Mediterranean coasts, thus extending through time, although under a new format, the "Ebro frontier" ecocultural segregation between northern moderns and Southern Neanderthals, the latter probably pushed at this time to refugia in the Southwest Atlantic seaboard and adjacent lands east of Gibraltar. Their eventual and rapid absorption once the core Continental populations recovered from the demographic crisis and started expanding was therefore predictable and inevitable, and is signalled, archaeologically, by the fact that, after about thirty-seven thousand years ago, the late MP is replaced throughout its entire range by the Aurignacian II (Zilhão et al. 20rob). At the other end of the continent, this expansion is signalled by the fact that people with an Aurignacian II or III-IV technology are now back in the Crimea and the middle Don, as documented at Kostenki I4 (level IIIa) and Siuren (Vishnyatsky \& Nehoroshev 2004), while isolated finds in Britain indicate that, in western Europe, resettlement reached as far as northern Wales (Jacobi 2007).

Given the pan-European distribution of the later Aurignacian, it is legitimate to suspect that significant ethnolinguistic diversity lies hidden under the pattern of homogeneity in technology, and there is indeed some evidence to that effect in the clear geographical clustering of ornament types (Vanhaeren \& d'Errico 2006). Despite some overlap, three macro-sets can be distinguished: Northern, formed by sites in Germany, Belgium and the Paris Basin, characterised by a repertoire of ivory beads (elongated, figure-eight-shaped, drop-shaped, disc-shaped) and pendants (zoomorphic, trapezoidal); Mediterranean, formed by sites in Spain, the Rhône Valley, Italy and Austria, characterised by marine shell beads; Western, formed by sites in the Aquitaine Basin and extending into the Pyrenees and Cantabria, characterised by perforated teeth (mostly of carnivores, but including human ones), beads and pendants shaped out of ivory or antler (rectangular, pointed, bilobate-notched, basket-shaped). Although the analysis conflated all subdivisions of the Aurignacian and included the Protoaurignacian too, the intraregional stability seen at stratified localities where variation across time can be assessed (e.g., Riparo Mocchi, in Italy, or the Geissenklösterle in Germany: Stiner I999; Conard \& Bolus 2003) supports the notion that the observed clustering reflects long-term patterns ultimately related to ethnolinguistic variation. 

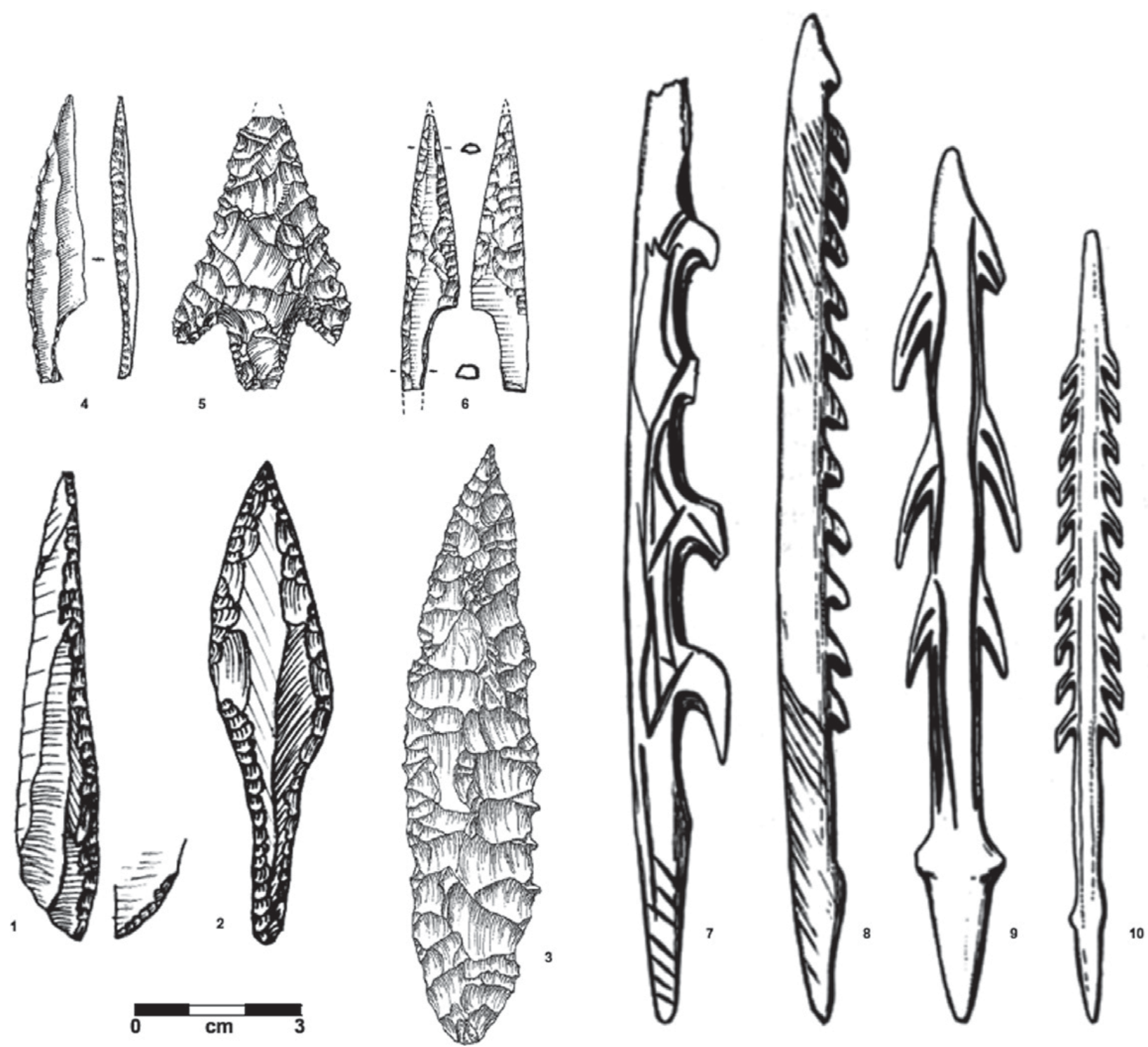

Figure 3.I9.6. Projectile points from the Full Phase of the Upper Palaeolithic. I. Gravette point (from Masnaigre, France; Gravettian); 2. Font-Robert point (from La Ferrassie, France; Gravettian); 3. Laurel-leaf point (from Galeria da Cisterna, Almonda, Portugal; Solutrean); 4. Backed and shouldered point (from Galeria da Cisterna, Almonda, Portugal; Solutrean); 5. Parpallò point (from Gruta do Caldeirão, Portugal; Solutrean); 6. Franco-Cantabrian shouldered point (from Fourneau du Diable, France; Solutrean). 7-Io. Bone/antler harpoons from the Magdalenian of France (7- La Madeleine; 8 - Bruniquel; 9 Sainte Eulalie; Io - Laugerie-Haute).

\section{The Full Phase}

The emergence of the Gravettian, during GI 7, about thirtyfive thousand years ago, is one of the least known periods of European Prehistory, but a gradual technological transition from the later Aurignacian can be envisaged (Zilhão I997; Pesesse 2010). Basically, what is at stake is a comeback to arming projectile shafts with stone tips instead of bone tips, and the utilisation of the backing technique to shape blade and bladelet blanks into sharp points (Fig. 3.I9.6); in central and eastern Europe, however, there are also foliate points in the beginning (Pavlovian, Molodovan) and shouldered points at the end (Willendorf-Kostenkian) (Svoboda 2007). The microlithic component of the toolkit follows the same trend, with backed bladelets functionally replacing the marginally trimmed Dufour bladelets of the Protoaurignacian and the Aurignacian.

Two widely shared traits confirm the impression of overall unity conveyed by basic lithic technology patterns and show that, at this time, the entire continent formed a single culture area crisscrossed by networks of exchange of information, people, artifacts and raw materials: the female figurines known as "Gravettian Venuses" (Soffer et al. 2000; see Chapter 3.20), 
so far only absent from Iberia; and the numerous burials that, from Sungir in Russia to Lagar Velho in Portugal, feature grave offerings and an extensive use of red ochre (Zilhão \& Trinkaus 2002; Zilhão 2005; Einwögerer et al. 2006). The number of individuals concerned - seventy-two - is in stark contrast with the fact that no burials were ever found in the Protoaurignacian and the Aurignacian, while the age of $\sim 34,250$ years ago obtained for the earliest (also the first ever to be excavated, the "Red Lady" of Paviland, Wales - in fact, a male individual; Jacobi \& Higham 2008) indicates that a change in religious beliefs was associated with the emergence of the Gravettian from the very beginning.

The funerary contexts of the Gravettian are novel not just in the sense that they reveal a change from how death was dealt with in the earlier UP but also in the sense that the age structure of the population of buried individuals is very particular (Zilhão \& Trinkaus 2002). While, in the MP, no differences between the different age classes are apparent, and the representation of foetuses and infants approaches expected mortality patterns, the burials of less than three-year-olds are, in the Gravettian, exceptional, and those of older children are always separated from the rest of the community - adults and children are found together neither in multiple graves nor in cave sites repeatedly used over time as interment localities. Moreover, in the only example known of a possible mass grave containing the remains of an entire community (Předmostí, in the Czech Republic; Klíma I99I), infants were clustered together, not individually associated with their putative parents - a pattern that still holds even if, alternatively, the site is interpreted as a focus for repeated, successive interment (Svoboda 2008). These observations suggest that the crossing of puberty was explicitly recognised as a major life-history event, perhaps signalling the crossing of a threshold whereby, once adolescents, individuals began to contribute to the group's productive activities and, as such, were deemed worthy of the same kind of treatment as adults - in death and, presumably, in life too.

In the few examples of prepuberty Gravettian burials, the associated ornaments are of the same types seen in the burials of adolescents and adults of the same region, suggesting that, at this time, personal ornaments primarily reflected ethnic affiliation (Vanhaeren \& d'Errico 2002). Moreover, at Sungir, the thousands of ivory beads decorating the clothes with which two juveniles had been interred head to head in a double burial are of the same type, but one-third smaller, than those found with an aged adult male buried elsewhere at the site (White 1999), and much the same observation has been made for the somewhat later child burial from La Madeleine, in France (the eponymous site of the Magdalenian culture; Vanhaeren \& d'Errico 200I). These cases suggest the existence of productions specifically designed for use by younger people, strengthening the argument for a differentiation of age classes derived from the burial evidence; whether this was a particular feature of the social structure of Gravettian (and later) UP peoples or a generalised feature of all the UP (and perhaps the MP too) is, however, an open issue, because such a differentiation may have been expressed in ways that do not preserve in the archaeological record.
The extraordinary richness of some of these juvenile burials, especially those from Sungir, has also been used to support the hypothesis that they reflect a non-egalitarian social structure, as, given their young ages, the high status inferred for them must have been ascribed rather than achieved (White 2003). Verification of the hypothesis, however, requires the establishment, for a given culture, in a given region and at a given time, that some children were treated at death in a way that significantly differs from the treatment given to the majority (Vanhaeren \& d'Errico 200I). Given the paucity of the data, such a verification is impossible at present, so the parsimonious view is that the richness of some juvenile UP burials simply reflects the affluence of the societies in which those children and adolescents lived (and, in Sungir, as among extant Arctic cultures, the plentiful leisure time available for craftsmanship in the long glacial winters during which people had to remain under shelter for extended, continuous periods of time).

Alternatively, it is possible that the rich burials of those juveniles reflect the fact that they were seen in life as spiritually important individuals, ones who, by their behaviour or anatomical idiosyncrasies (or abnormalities), were perceived as privileged interlocutors with the mythological beings or with the other worlds of the cosmovisions of UP peoples. In this respect, it must be noted that of the twenty-nine sufficiently complete juveniles and adults that were buried in the Gravettian, a high percentage (31\%) are pathologically unusual (i.e., display abnormalities that go beyond the minor trauma and healing related to a mobile way of life), which is all the more remarkable because the skeletal evidence as a whole shows that these populations were in quite good health (Holt \& Formicola 2008; Trinkaus \& Buzhilova 2010). The unusual pathologies include (a) congenital or inherited diseases (such as inner ear malformation resulting in hearing deficiency, bowing of the long bones possibly in relation to a diabetic condition of the mother, and skeletal malformations related to abnormal calcification of the joints), (b) chronical infections (periostitis and histiocytosis), (c) deformations caused by major trauma, and (d) in the case of the Sungir I adult individual, death provoked by a projectile. This pattern extends to the Magdalenian/ Late Epigravettian, as exemplified by the dwarf from the cave of Romito in Italy. The fact that the most severely handicapped individuals (Sungir 3, Dolní Věstonice I5, Romito 2) occur in double or triple burials has even led to speculations that the death of prominent people was at times accompanied by human sacrifices (Formicola 2007); this is unlikely, as manpower is a scarce and valuable resource in hunter-gatherer societies, but that the hypothesis has been entertained still serves to highlight the extent to which these graves are indeed exceptional.

Some of the Gravettian female figurines (namely, the famous Venus from Willendorf, in Austria) correspond to anatomically very accurate renditions of clinically obese women (Trinkaus $2005 \mathrm{~b})$. Since the most common cause of human obesity is an imbalance between calorie intake and energy expenditure, it makes sense to relate the familiarity with the phenomenon implied by the realism of the artistic renderings with ways of life characterised by seasonally or annually reduced mobility. 
Bearing in mind the burial evidence, however, it may also be the case that the art is in these cases portraying the exceptional rather than the banal, that is, individuals whose unusual physical appearance was caused by one of the rare metabolic disorders that can also generate obsesity and whose particular bodily attributes may have helped in raising them to high status. In this vein, note that, at the Czech locality of Dolní Věstonice, a buried individual whose cranium displays lesions caused by a single heavy blow to the left side may be represented in a small mammoth-ivory portrait found elsewhere at the site that features a marked facial asymmetry consistent with the nature of those lesions (Trinkaus \& Svoboda 2006).

By twenty-five thousand years ago, this culturally sophisticated hunter-gatherer civilisation had come to an end. In Italy, in parts of the middle Danube Basin and in the Balkans, the subsequent millennia witness basic continuity in stone tool technology, which is reflected in the designations used by archaeologists to refer to the techno-complexes of the periodEpigravettian or Tardigravettian. As the LGM approached, however, the European Plains to the north became devoid of permanent human settlement, and a new techno-complex emerged west of the Rhône: the Solutrean, characterised by a number of unifacially and bifacially flaked stone-point types that pattern in a very regular way in both time and space, especially in the Upper Solutrean Phase, which develops in the few centuries around twenty-three thousand years ago (Fig. 3.I9.6). A study of the relationship between the cultural territories delimited by point-type distributions and the environmental characteristics of those territories as inferred from palaeoclimatic data showed a remarkable correspondence between the observed archaeological distributions and the reconstructed ecological niches (Banks et al. 2009). The size of those territories, smaller than the macroregions revealed by the distribution of the personal ornaments of earlier periods, broadly corresponds, under population densities typical of subarctic conditions, to what one would expect for ethnic entities of the dialect tribe kind (Hill 1978).

Does this pattern stand for the emergence of more structured forms of social organisation and interaction in the Solutrean, or simply for this being the first time that such well-structured forms can be read in the archaeological record of Europe? Although the first hypothesis cannot be rejected, the second is more likely, considering that two important features of the Solutrean are very relevant in this regard: (a) the greater plasticity of bifacial flaking fosters much greater variation in point morphology than is possible when simply backing or trimming a blank, and (b) the easy recognition of such unique and characteristic point types allows the inclusion of even isolated occurrences in the distribution maps, thereby significantly increasing the spatial resolution of the analyses. Bearing this in mind, the combined evidence from stone tools and ornaments suggests the existence since at least the Early UP of a three-tier system of social networks (Zilhão 1997): the dialect tribe, revealed by the distribution of specific Solutrean point types; the language area, apparent in the permanence over time, from the Aurignacian to the Gravettian, of macroregional clusters of personal-ornament types with the same approximate boundaries; and the techno-complex or culture area, reflected in the vast supra-regional or even continentwide expanses over which stone-tool technologies spread and in the simultaneity with which they changed along similar lines across such vast expanses.

In France the Upper Solutrean is replaced by the Badegoulian after $\sim 22,500$ years ago, through a technological transition that remains poorly known (Ducasse 2010). In the Iberian east, south and southwest, the so-called Solutreogravettian (defined by backed-and-shouldered points with a tendency for microlithisation towards the end) occupies the corresponding culture-stratigraphic slot, while the intermediate Languedoc region of Mediterranean France features a Badegoulian with Solutreogravettian elements. The common thread, especially in the Badegoulian, is the comeback of the bone/antler point, heralding the development of the successful, spearthroweraided weapons system of the Magdalenian that, after about twenty thousand years ago, spread across all of western Europe and, as deglaciation advanced, to central and northern Europe too.

Combining the osseous point with a range of microlithic types, mostly backed bladelets, the Magdalenian also saw the development of new kinds of bone tools, namely, the harpoon (Fig. 3.19.6). The designation reflects the inference that these barbed points with a perforation at the base were detachable elements stringed to the projectile's shaft, of the kind used in the ethnographic Arctic to hunt marine mammals. Currently, the designation is retained, but its functional underpinnings are under scrutiny, with many authors arguing that no direct proof of detachability exists and that the presence of Magdalenian "harpoons" in interior, continental areas is suggestive of their being simply a new variety of projectile tip designed to increase the efficiency of the hunt (Pétillon 2008). Coming at the end of the Magdalenian sequence, this innovation fits the pattern of increased adaptive success generating population growth discussed in this chapter for the post-LGM Period on the basis of the eastern European evidence. In western Europe, a good measure of that success resides in the explosion of artistic activity that resulted in the production of two masterpieces of all time, the decorated cave of Lascaux (France) and the polychrome ceiling from the cave of Altamira (Spain) (see Chapter 3.20).

\section{The Final Phase}

The last three millennia of the UP coincide with the end of the Last Glacial, a period characterised by the continued retreat of mountain glaciers and the Fennoscandinavian ice sheet, sealevel rise, and woodland expansion. In this context, two things would be expected to occur: firstly, a northward extension of the human range, as indeed documented by settlements in southern Sweden and southern Norway dated to around II,500 years ago (Bratlund I996); secondly, a fragmentation of pan-Continental interaction networks, as indeed apparent in the multiplication of industrial facies, of which only some were retained in Table 3.I9.I. 
These facies feature idiosyncrasies clearly patterned along regional rather than functional or chronological lines, although all respond to the same concept, one that, in keeping with the notion that the bow-and-arrow was invented at about this time, revolves around the microlithic projectile point. That the invention, wherever it occurred, diffused and rapidly became widespread is indicated by the fact that all archaeological cultures of this Final Phase represent a break with the patterns of technological change seen in the preceding UP. Across the thirty thousand years of the Transitional, Early and Full phases, we see alternating periods of preference for either stone or bone as the raw material of choice for the manufacture of projectile points, which, even when small, featured size ranges extending beyond that of the arrow-tip to encompass those of the dart- or the spear-tip. In the Final Phase, the bone points of the Magdalenian all but disappear but are not replaced by functionally equivalent stone ones - with regional variations, only microlithic points in the size range of the arrowhead are now being manufactured across the board.

The increased territorialisation suggested by the level and nature of the formal variation of those microliths is also apparent in the realm of physical anthropology (Holt 2003). Stature, for instance, decreased dramatically in post-LGM populations, with no significant change in body proportions occurring in parallel, which suggests that factors other than long-term climatic adaptation were at work in this process. A decline in the quality of the diet may explain the pattern, but there is no evidence that such a decline occurred, so a more likely explanation is an increased level of inbreeding, which, in modern populations, is known to cause a reduction in stature. Decreased mobility is an expected corollary of increased territorialisation and inbreeding, so the fact that the structural properties of the lower limb bones reveal a significant contrast between preLGM and post-LGM Europeans in the amount of walking and running around, continuing into the Mesolithic, is consistent with the material culture patterns.

\section{Concluding Remarks}

The evidence reviewed here suggests a causal link between technological innovation, leading to more efficient hunting weaponry and, ultimately, population growth, at two points in the European UP sequence. In the first, reflected in the emergence of figurative art after $\sim 37,500$ years ago, the cause would lie in the generalised adoption of lighter, standardised hunting weapons - throwing spears or javelins. In the second, about twenty thousand years later, the cause would lie in the invention of the spearthrower-and-dart. As discussed by Childe (1936), however, technical progress and demographic expansion tend to form a feedback loop, and we must therefore also entertain the hypothesis that the reverse mechanism - of population growth triggering the search for and eventual cracking of technical improvements that secured the higher extractive efficiency required to feed the additional mouths - may also have been in operation. For instance, the stimulus for the development of the methods of stone-tool production emphasising quantity and standardisation that underpin the very conceptual substance of the UP and relate to the replacement of the thrusting spear by the javelin may have resided in the need to accommodate continued demographic expansion once the MIS 3 recolonisation of the vast areas of central and northern Europe that had become deserted in MIS four times resulted in the filling-up of the newly available land.

By the same token, the bow-and-arrow and the domestication of the dog may have come about as a technological response to continued, even if slow, population growth as the post-LGM recolonisation of the same areas was completed and more effective hunting methods than even the spearthrowerand-dart of the early Magdalenian were required. If this logic is accepted, the European UP would show - with hiccups and setbacks caused by catastrophic events or adverse environmental change - the operation of an exponential process of population pressure: adaptive success, reflected in demographic expansion, triggered by and leading to technological innovation or economic intensification, in turn bringing about further population growth. In an evolutionary perspective, the UP may thus be conceptualised as a "revolution" triggered by the same kinds of mechanisms envisaged by Childe's (1936) "Neolithic Revolution" (Gilman I984; Bar-Yosef I998; Kozłowski 2002). A tipping point was reached at the end of the last glacial, leading to the systematic exploitation of food stuffs much lower in the trophic chain, until then of secondary importance only. In the Near East, these developments eventually led to the emergence of the Neolithic. That, for a while, Europe was to follow a different path is probably due to the lack of suitable potential domesticables (Diamond 1997). Under this perspective, the emergence of agro-pastoral economies simply enhanced (beyond recognition, certainly, and on a totally different scale) trends that had deep roots in the preceding millennia of hunter-gatherer (pre-)history.

\section{Acknowledgements}

Paul Bahn, Erik Trinkaus and Paola Villa read preliminary drafts and contributed critical comments and useful information. Any errors or omissions are, however, my own only.

\section{References}

Adler, D. S., Bar-Oz, G., Belfer-Cohen, A. \& Bar-Yosef, O. 2006. Ahead of the game. Middle and Upper Palaeolithic hunting behaviors in the southern Caucasus. Current Anthropology 47 (I): 89-II8.

Almeida, F., Brugal, J.-P., Zilhão, J. \& Plisson, H. 2006. An Upper Palaeolithic Pompeii: technology, subsistence and palaeoethnography at Lapa do Anecrial, pp. II9-39 in (N. Bicho, ed.) From the Mediterranean basin to the Atlantic shore: Papers in Honor of Anthony Marks. Actas do IV Congresso de Arqueologia Peninsular. Promontoria Monográfica 07. Universidade do Algarve: Faro.

Almeida, F., Moreno-García, M. \& Angelucci, D. E. 2009. From under the bulldozer's claws: the EEI5 Late Gravettian 
occupation surface of the Lagar Velho rock-shelter. World Archaeology 4I (2): 242-6I.

Anikovich, M. V., Sinitsyn, A. A., Hoffecker, J. F., Holliday, V. T., Popov, V. V., Lisitsyn, S. N., Forman, S. L., Levkovskaya, G. M., Pospelova, G. A., Kuz'mina, I. E., Burova, N. D., Goldberg, P., Macphail, R. I., Giaccio, B. \& Praslov, N. D. 2007. Early Upper Palaeolithic in eastern Europe and implications for the dispersal of modern humans. Nature 315: 223-6.

Antunes, M. T. (ed.) 2000. Últimos Neandertais em Portugal. Evidência, odontológica e outra. Academia das Ciências: Lisbon.

Aranguren, B., Becattini, R., Lippi, M. M. \& Revedin, A. 2007. Grinding flour in Upper Palaeolithic Europe (25 000 years BP). Antiquity 8I: 845-55.

Aubry, T., Mangado, X., Sampaio, J. \& Sellami, F. 2002. Open-air rock-art, territories and modes of exploitation during the Upper Palaeolithic in the Côa Valley (Portugal). Antiquity 76 : $62-76$.

Aura, J. E., Villaverde, V., Pérez Ripoll, M., Martínez Valle, R. \& Calatayud, P. G. 2002a. Big game and small prey: Palaeolithic and Epipalaeolithic economy from Valencia (Spain). Journal of Archaeological Method and Theory 9 (3): 215-68.

Aura, J. E., Jordá, J., Morales, J. V., Pérez, M., Villalba, M.-P. \& Alcover, J. A. 2009. Economic transitions in finis terra: the western Mediterranean of Iberia, I5-7 ka BP. Before Farming $2009 / 2$, article 4 .

Aura, J. E., Jordá, J., Pérez, M., Rodrigo, M. J., Badal, E. \& Guillem, P. 2002b. The far south: the Pleistocene-Holocene transition in Nerja Cave (Andalucía, Spain). Quaternary International 93-4: 19-30.

Bahn, P. \& Vertut, J. 1997. Journey through the Ice Age. Weidenfeld \& Nicolson: London.

Banks, W. E., Zilhão, J., d'Errico, F., Kageyama, M., Sima, A. \& Ronchitelli, A. 2009. Investigating links between ecology and bifacial tool types in western Europe during the Last Glacial Maximum. Journal of Archaeological Science 36 (I2): 2853-67.

Baptista, A. M. 2009. O Paradigma Perdido. O Vale do Côa e a Arte Palaeolítica de Ar Livre em Portugal. Parque Arqueológico do Vale do Côa/Edições Afrontamento: Vila Nova de Foz Côa/Porto.

Bar-Yosef, O. 1998. On the nature of transitions: the Middle to Upper Palaeolithic and the Neolithic Revolution. Cambridge Archaeological Journal 8 (2): I4I-63.

2004. Eat what is there: hunting and gathering in the world of Neanderthals and their neighbours. International Journal of Osteoarchaeology I4: 333-42.

Bar-Yosef, O., Arnold, M., Mercier, N., Belfer-Cohen, A., Goldberg, P., Housley, R., Laville, H., Meignen, L., Vogel, J. C. \& Vandermeersch, B. 1996. The dating of the Upper Palaeolithic layers in Kebara Cave, Mt Carmel. Journal of Archaeological Science 23: 297-306.

Bar-Yosef, O. \& Belfer-Cohen, A. 2010. The Levantine Upper Palaeolithic and Epipalaeolithic, pp. ${ }^{44-67}$ in (E. A. A. Garcea, ed.) South-Eastern Mediterranean Peoples between 130,000 and 10,000 Years Ago. Oxbow: Oxford.

Bar-Yosef, O. \& Kuhn, S. r999. The big deal about blades: laminar technologies and human evolution. American Anthropologist IOI (2): $322-38$.

Bergman, C. A. 1993. The development of the bow in western Europe: a technological and functional perspective, pp. 95-105 in (G. L. Peterkin, H. M. Bricker \& P. Mellars, eds.) Hunting and Animal Exploitation in the Later Palaeolithic and Mesolithic of Eurasia. Archaeological Papers of the American Anthropological Association 4: Washington, DC.
Binford, L. 1983. In Pursuit of the Past. Thames \& Hudson: London.

Blasco, R. 2008. Human consumption of tortoises at Level IV of Bolomor Cave (Valencia, Spain). Journal of Archaeological Science $35: 2839-48$.

Blasco, R. \& Fernández, J. 2009. Middle Pleistocene bird consumption at Level XI of Bolomor Cave (Valencia, Spain). Journal of Archaeological Science 36: 2213-23.

Bolus, M. \& Conard, N. J. 2006. Zur Zeitstellung von Geschossspitzen aus organischen Materialien im späten Mittelpaläolithikum und Aurignacien. Archäologisches Korrespondenzblatt 36 (I): I-I5.

Bon, F. 2002. L'Aurignacien entre mer et océan. Réflexion sur l'unité des phases anciennes de l'Aurignacien dans le sud de la France. Mémoire de la Société Préhistorique Française 29: Paris.

Bordes, J.-G. 2006. News from the West: a reevaluation of the classical Aurignacian sequence of the Périgord, pp. I47-7I in (O. Bar-Yosef \& J. Zilhão, eds.) Towards a Definition of the Aurignacian, Trabalhos de Arqueologia 45. American School of Prehistoric Research/Instituto Português de Arqueologia: Lisbon.

Bosinski, G. I990. Homo sapiens. L'histoire des chasseurs du Paléolithique supérieur en Europe (40 000-10 000 avant J.-C.). Errance: Paris.

Bouzouggar, A., Barton, N., Vanhaeren, M., d'Errico, F., Collcutt, S., Higham, T., Hodge, E., Parfitt, S., Rhodes, E., Schwenninger, J.-L., Stringer, C., Turner, E., Ward, S., Moutmir, A. \& Stambouli, A. 2007. 82,000-year-old shell beads from North Africa and implications for the origins of modern human behavior. Proceedings of the National Academy of Sciences USA Io4 (24): 9964-9.

Bradley, R. S. 1999. Palaeoclimatology. Reconstructing Climates of the Quaternary. 2nd ed. International Geophysics Series 68, Elsevier: San Diego.

Bratlund, B. 1996. Hunting strategies in the Late Glacial of northern Europe: a survey of the faunal evidence. Journal of World Prehistory Io (I): I-48.

Brugal, J. P. 2006. Petit gibier et fonction de sites au Paléolithique Supérieur: les ensembles fauniques de la grotte d'Anecrial (Porto de Mós, Estremadure, Portugal). Paléo I8: 45-68.

Castel, J.-C., Chadelle, J.-P. \& Geneste, J.-M. 2005. Nouvelle approche des territoires solutréens du sud-ouest de la France, pp. 279-94 in (J. Jaubert \& M. Babaza, eds.) Territoires, déplacements, mobilité, échanges durant la Préhistoire. Terres et hommes du Sud. CTHS: Paris.

Castel, J.-C., Liolios, D., Laroulandie, V., Chauvière, F.-X., Chadelle, J.-P., Pike-Tay, A. \& Geneste, J.-M. 2006. Solutrean animal resource exploitation at Combe Saunière (Dordogne, France), pp. ${ }^{2} 3^{8-52}$ in (M. Maltby, ed.) Integrating Zooarchaeology. Oxbow: Oxford.

Cattelain, P. I989. Un crochet de propulseur solutréen de la grotte de Combe-Saunière I (Dordogne). Bulletin de la Société Préhistorique Française 86: 213-I6.

Childe, V. G. 1936. Man Makes Himself. Watts: London.

Cochard, D. \& Brugal, J.-P. 2004. Importance des fonctions de sites dans les accumulations paléolithiques de léporidés, pp. $217-30$ in (J.-P. Brugal \& J. Desse, eds.) Petits animaux et sociétés humaines. Du complément alimentaire aux ressources utilitaires. Éditions APDCA: Antibes.

Conard, N. J. 2003. Palaeolithic ivory sculptures from southwestern Germany and the origins of figurative art. Nature 426 : $830-2$.

Conard, N. J. \& Bolus, M. 2003. Radiocarbon dating the appearance of modern humans and timing of cultural innovations 
in Europe: new results and new challenges. Journal of Human Evolution 44: 33I-7I.

Costamagno, S. 2000. Stratégies d'approvisionnement et traitement des carcasses au Magdalénien: l'exemple de MoulinNeuf (Gironde). Paléo I2: 77-95.

200I. Exploitation de l'Antilope saïga au Magdalénien en Aquitaine. Paléo I3: III-28.

Davis, S. J. M. 1987. The Archaeology of Animals. Routledge: London.

Davis, S. J. M. \& Valla, F. R. I978. Evidence for domestication of the dog 12,000 years ago in the Natufian of Israel. Nature 276 : 608-10.

Delpech, F. 1983. Les faunes du Paléolithique supérieur dans le sud-ouest de la France. Cahiers du Quatemaire 6, Centre National de la Recherche Scientifique: Paris.

Delpech, F., Grayson, D. K. \& Rigaud, J.-P. 2000. Biostratigraphie et paléoenvironnements du début du Würm recent d'après les grands mammifêres de l'abri du Flageolet I (Dordogne, France). Paléo I2: 97-I26.

Delpech, F. \& Texier, J.-P. 2007. Approche stratigraphique des temps gravettiens: l'éclairage aquitain. Paléo I9: 15-30.

Demars, P.-Y. \& Laurent, P. I989. Types d'outils lithiques du Paléolithique supérieur en Europe. Centre National de la Recherche Scientifique: Paris.

Detry, C. \& Cardoso, J. L. 20Io. On some remains of dog (Canis familiaris) from the Mesolithic shell-middens of Muge, Portugal. Journal of Archaeological Science 37: 2762-74.

Diamond, J. I997. Guns, Germs and Steel. W. W. Norton: New York.

Dobo, A., Soficaru, A. \& Trinkaus, E. 2010. The Prehistory and Paleontology of the Peştera Muierii, Romania. Études et Recherches Archéologiques de l'Université de Liège I24: Liège.

Dolukhanov, P., Sokoloff, D. \& Shukurov, A. 200I. Radiocarbon chronology of Upper Palaeolithic sites in eastern Europe at improved resolution. Journal of Archaeological Science 28: 699-7I2.

Drucker, D. \& Henry-Gambier, D. 2005. Determination of the dietary habits of a Magdalenian woman from Saint-Germain-laRivière in southwestern France using stable isotopes. Journal of Human Evolution 49: 19-35.

Duarte, C., Maurício, J., Pettitt, P. B., Souto, P., Trinkaus, E., Van der Plicht, H. \& Zilhão, J. 1999. The Early Upper Palaeolithic human skeleton from the Abrigo do Lagar Velho (Portugal) and modern human emergence in Iberia. Proceedings of the National Academy of Sciences USA 96: 7604-9.

Ducasse, S. 20I0. La "parenthèse" badegoulienne: fondements et statut d'une discordance industrielle au travers de l'analyse techno-économique de plusieurs ensembles lithiques méridionaux du Dernier Maximum Glaciaire. Ph.D. dissertation, University of Toulouse 2.

Einwögerer, T., Friesinger, H., Händel, M., NeugebauerMaresch, C., Simon, U. \& Teschler-Nicola, M. 2006. Upper Palaeolithic infant burials. Decorations on the bodies of newborns indicate that they were probably important in their community. Nature 444: 285 .

Enloe, J. 2003. Acquisition and processing of reindeer in the Paris Basin, pp. 23-3I in (S. Costamagno \& V. Laroulandie, eds.) Zooarchaeological Insights into Magdalenian Lifeways. British Archaeological Reports International Series II44: Oxford.

d'Errico, F. 2003. The invisible frontier. A multiple species model for the origin of behavioral modernity. Evolutionary Anthropology 12: 188-202.

d'Errico, F., Borgia, V. \& Ronchitelli, A. 2012. Uluzzian bone technology and its implications for the origin of behavioural modernity. Quaternary International 259: 59-7I.
d'Errico, F., Henshilwood, C., Lawson, G., Vanhaeren, M., Tillier, A.-M., Soressi, M., Bresson, F., Maureille, B., Nowell, A., Lakarra, J., Backwell, L. \& Julien, M. 2003a. Archaeological evidence for the emergence of language, symbolism, and music - an alternative multidisciplinary perspective. Journal of World Prehistory I7 (I): I-70.

d'Errico, F., Julien, M., Liolios, D., Vanhaeren, M. \& Baffier, D. 2003b. Many awls in our argument. Bone tool manufacture and use in the Châtelperronian and Aurignacian levels of the Grotte du Renne at Arcy-sur-Cure, pp. 247-70 in (J. Zilhão \& F. d'Errico, eds.) The Chronology of the Aurignacian and of the Transitional Technocomplexes: Dating, Stratigraphies, Cultural Implications. Trabalhos de Arqueologia 33, Instituto Português de Arqueologia: Lisbon.

d'Errico, F. \& Sánchez-Goñi, M. F. 2003. Neandertal extinction and the millennial scale climatic variability of OIS 3. Quaternary Science Reviews 22: 769-88.

d'Errico, F., Vanhaeren, M., Barton, N., Bouzouggar, A., Mienis, H., Richter, D., Hublin, J.-J., McPherron, S. P. \& Lozouet, P. 2009. Additional evidence on the use of personal ornaments in the Middle Palaeolithic of North Africa. Proceedings of the National Academy of Sciences USA ro6 (38): 16,05I-6.

d'Errico, F., Zilhão, J., Baffier, D., Julien, M. \& Pelegrin, J. 1998. Neanderthal acculturation in western Europe? A critical review of the evidence and its interpretation. Current Anthropology 39, Supplement: SI-S44.

Féblot-Augustins, J. 2008. Palaeolithic raw material provenance studies, pp. II 87-98 in (D. M. Pearsall, ed.) Encyclopedia of Archaeology, vol. 2. Elsevier: New York.

2009. Revisiting European Upper Palaeolithic raw material transfers: the demise of the cultural ecological paradigm?, pp. $25-46$ in (B. Adams \& B. S. Blades, eds.) Lithic Materials and Palaeolithic Societies. Blackwell: London.

Fedele, F. G., Giaccio, B. \& Hajdas, I. 2008. Timescales and cultural process at 40,000 BP in the light of the Campanian Ignimbrite eruption, western Eurasia. Journal of Human Evolution 55: 834-57.

Fedele, F. G., Giaccio, B., Isaia, R. \& Orsi, G. 2003. The Campanian Ignimbrite eruption, Heinrich Event 4, and Palaeolithic change in Europe: a high-resolution investigation, pp. $30 \mathrm{I}-25$ in (A. Robock \& C. Oppenheimer, eds.) Volcanism and the Earth's Atmosphere. Geophysical Monograph I39: Washington, DC.

Fletcher, W. J., Sánchez-Goñi, M. F., Allen, J. R. M., Cheddadi, R., Combourieu-Nebout, N., Huntley, B., Lawson, I., Londeix, L., Magri, D., Margari, V., Müller, U. C., Naughton, F., Novenko, E., Roucoux, K. \& Tzedakis, P. C. 20ro. Millennialscale variability during the last glacial in vegetation records from Europe. Quaternary Science Reviews 29: 2839-64.

Fontana, L. 2000. La chasse au renne au Paléolithique Supérieur dans le Sud-Ouest de la France: nouvelles hypothèses de travail. Paléo I2: I4I-64.

Fontana, L. \& Chauvière, F.-X. 2009. The total exploitation of reindeer at the site of Les Petits Guinards. What's new about the annual cycle of nomadism of Magdalenian groups in the French Massif Central?, pp. IOI-II in (L. Fontana, F.-X. Chauvière \& A. Bridault, eds.) In Search of Total Animal Exploitation. Case Studies from the Upper Palaeolithic and Mesolithic. British Archaeological Reports International Series 2040: Oxford.

Formicola, V. 2007. From the Sunghir children to the Romito dwarf: aspects of the Upper Palaeolithic funerary landscape. Current Anthropology 48 (3): 446-53. 
Gamble, C. I983. Culture and society in the Upper Palaeolithic of Europe, pp. 20I-II in (G. Bailey, ed.) Hunter-Gatherer Economy in Prehistory. A European Perspective. Cambridge University Press: Cambridge.

1999. The Palaeolithic Societies of Europe. Cambridge University Press: Cambridge.

Gamble, C., Davies, W., Pettitt, P., Hazelwood, L. \& Richards, M. 2006. The Late Glacial ancestry of Europeans: combining genetic and archaeological evidence. Documenta Praehistorica 33: I-IO.

García-Moro, C., Hernández, M. \& Lalueza, C. I997. Estimation of the optimum density of the Selk'nam from Tierra del Fuego: inferences about human dynamics in extreme environments. American Journal of Human Biology 9: 699-708.

Germonpré, M., Sablin, M. V., Stevens, R. E., Hedges, R. E. M., Hofreiter, M., Stiller, M. \& Després, V. R. 2009. Fossil dogs and wolves from Palaeolithic sites in Belgium, the Ukraine and Russia: osteometry, ancient DNA and stable isotopes. Journal of Archaeological Science 36: 473-90.

Gilman, A. 1984. Explaining the Upper Palaeolithic revolution, pp. II5-26 in (M. Spriggs, ed.) Marxist Perspectives in Archaeology. Cambridge University Press: Cambridge.

González-Morales, M. \& Straus, L. G. 2009. Extraordinary Early Magdalenian finds from El Mirón Cave, Cantabria (Spain). Antiquity 83: 267-8I.

Gordon, B. 1988. Of Men and Reindeer Herds in French Magdalenian Prehistory. British Archaeological Reports International Series 390: Oxford.

Graburn, N. 1979. Indian-Eskimo relations. Arctic Anthropology 16 (2): 184-95.

Grayson, D. K. \& Delpech, F. 2002. Specialized Early Upper Palaeolithic hunters in southwestern France? Journal of Archaeological Science 29: 1439-49.

Green, R. E., Krause, J., Briggs, A. W., Maricic, T., Stenzel, U., Kircher, M., Patterson, N., Li, H., Zhai, W., Fritz, M. H.-Y., Hansen, N. F., Durand, E. Y., Malaspinas, A.-S., Jensen, J., Marques-Bonet, T., Alkan, C., Prüfer, K., Meyer, M., Burbano, H. A., Good, J. M., Schultz, R., Aximu-Petri, A., Butthof, A., Höber, B., Höffner, B., Siegemund, M., Weihmann, A., Nusbaum, C., Lander, E. S., Russ, C., Novod, N., Affourtit, J., Egholm, M., Verna, C., Rudan, P., Brajkovic, D., Kucan, Ž., Gusič, I., Doronichev, V. B., Golovanova, L. V., Lalueza-Fox, C., de la Rasilla, M., Fortea, J., Rosas, A., Schmitz, R. W., Johnson, P. L. F., Eichler, E. E., Falush, D., Birney, E., Mullikin, J. C., Slatkin, M., Nielsen, R., Kelso, J., Lachmann, M., Reich, D. \& Pääbo, S. 2010. A draft sequence of the Neandertal genome. Science 328: 710-22.

Harrison, S. P. \& Sánchez-Goñi, M. F. 20Io. Global patterns of vegetation response to millennial-scale variability and rapid climate change during the last glacial period. Quaternary Science Reviews 29: 2957-80.

Hedges, R. E. M. \& Reynard, L. M. 2007. Nitrogen isotopes and the trophic level of humans in archaeology. Journal of Archaeological Science 34: 1240-5I.

Higham, T. F. G., Bronk Ramsey, C., Karavanić, I., Smith, F. H. \& Trinkaus, E. 2006b. Revised direct radiocarbon dating of the Vindija GI Upper Paleolithic Neandertals. Proceedings of the National Academy of Sciences USA I03 (3): 553-7.

Higham, T. F. G., Jacobi, R. M. \& Bronk Ramsey, C. 2006a. AMS radiocarbon dating of ancient bone using ultrafiltration. Radiocarbon 48 (2): 179-95.
Higham, T. F. G., Jacobi, R. M., Julien, M., David, F., Basell, L., Wood, R., Davies, W. \& Bronk Ramsey, C. 20I0. Chronology of the Grotte du Renne (France) and implications for the context of ornaments and human remains within the Châtelperronian. Proceedings of the National Academy of Sciences USA I07 (47): 20,234-9.

Hill, J. H. 1978. Language contact systems and human adaptations. Journal of Anthropological Research 34 (I): I-26.

Hoffecker, J. F. 2005. Innovation and technological knowledge in the Upper Paleolithic of northern Eurasia. Evolutionary Anthropology I4: 186-98.

Holt, B. M. 2003. Mobility in Upper Palaeolithic and Mesolithic Europe: evidence from the lower limb. American Journal of Physical Anthropology I22: 200-I5.

Holt, B. M. \& Formicola, V. 2008. Hunters of the Ice Age: the biology of Upper Palaeolithic people. Yearbook of Physical Anthropology 51: 70-99.

Hughes, S. S. 1998. Getting to the point: evolutionary change in prehistoric weaponry. Journal of Archaeological Method and Theory 5 (4): 345-408.

Hutchings, W. K. \& Bruchert, L. W. 1997. Spearthrower performance: ethnographic and experimental research. Antiquity 7I: 890-7.

Iakovleva, L. \& Djindjian, F. 2005. New data on mammoth bone settlements of eastern Europe in the light of the new excavations of the Gontsy site (Ukraine). Quaternary International I26-8: 195-207.

Jacobi, R. 2007. A collection of Early Upper Palaeolithic artefacts from Beedings, near Pulborough, West Sussex, and the context of similar finds from the British Isles. Proceedings of the Prehistoric Society 73: 229-325.

Jacobi, R. \& Higham, T. F. G. 2008. The "Red Lady" ages gracefully: new ultrafiltration AMS determinations from Paviland. Journal of Human Evolution 55: 898-907.

Jacobi, R., Higham, T. F. G., Haesaerts, T., Jadin, I. \& Basell, L. S. 20I0. Radiocarbon chronology for the Early Gravettian of northern Europe: new AMS determinations for MaisièresCanal, Belgium. Antiquity 84: 26-40.

Jochim, M., Herhahn, C. \& Starr, H. 1999. The Magdalenian colonization of southern Germany. American Anthropologist IOI (I): I29-42.

Jones, E. L. 2007. Subsistence change, landscape use, and changing site elevation at the Pleistocene-Holocene transition in the Dordogne of southwestern France. Journal of Archaeological Science 34: 344-53.

2009. Climate change, patch choice, and intensification at Pont d'Ambon (Dordogne, France) during the Younger Dryas. Quaternary Research 72: 371-6.

Klein, R. G. 2003. Whither the Neanderthals? Science 299: I525-7.

Klíma, B. r99r. Das paläolithische Massengrab von Předmostí, Versuch einer Rekonstruktion. Quartär 4I-2: I87-94.

Kozłowski, J. 2002. Les premiers hommes modernes et les premiers agriculteurs en Europe: voies de diffusion et interactions entre populations, pp. 9-34 in (M. Otte \& J. Kozlowski, eds.) Préhistoire de la grande plaine du Nord de l'Europe. Les échanges entre l'Est et l'Ouest dans les sociétés préhistoriques. Études et Recherches Archéologiques de l'Université de Liège 99: Liège.

Kuhn, S. \& Stiner, M. 2006. What's a mother to do? The division of labor among Neandertals and modern humans in Eurasia. Current Anthropology 47 (6): 953-80.

Layton, R. 1992. Australian Rock Art: A New Synthesis. Cambridge University Press: Cambridge. 
Le Gall, O. \& Pannoux, P. 1994. Les poissons de Pont d'Ambon. Gallia Préhistoire 36: II3-26.

Lombard, M. \& Phillipson, L. 20ro. Indications of bow and stonetipped arrow use 64 ooo years ago in KwaZulu-Natal, South Africa. Antiquity 84: 635-48.

Marks, A. E. \& Monigal, K. 2004. Origins of the European Upper Palaeolithic, seen from Crimea. Simple myth or complex reality?, pp. 64-79 in (P. J. Brantingham, S. L. Kuhn \& K. W. Kerry, eds.) The Early Upper Palaeolithic beyond Western Europe. University of California Press: Berkeley.

Meignen, L. \& Bar-Yosef, O. 2004. Réflexions sur la fin du Paléolithique moyen et les débuts du Paléolithique supérieur au Proche Orient, pp. 235-46 in (Le Secrétariat du Congres, ed.) Actes du XIVème Congrès UISPP, Section 5, Le Paléolithique Moyen. BAR International Series I239: Oxford.

Mellars, P. A. 1973. The character of the Middle-Upper Palaeolithic transition in South-west France, pp. $255-76$ in (C. Renfrew, ed.) The Explanation of Cultural Change: Models in Prehistory. Duckworth: London.

Mellars, P. A. 2004a. Neanderthals and the modern human colonization of Europe. Nature 432: 46I-5.

2004b. Reindeer specialization in the early Upper Palaeolithic: the evidence from South west France. Journal of Archaeological Science 31: 613-17.

2005. The impossible coincidence: a single-species model for the origins of modern human behavior in Europe. Evolutionary Anthropology I4: 12-27.

20I0. Neanderthal symbolism and ornament manufacture: the bursting of a bubble? Proceedings of the National Academy of Sciences USA 107 (47): 20,147-8.

Mellars, P. A. \& Stringer, C. B. (eds.) I989. The Human Revolution. Edinburgh University Press: Edinburgh.

Mena, F. 1997. Middle and Late Holocene adaptations in Patagonia, pp. 46-59 in (C. McEwan, L. A. Borrero \& A. Prieto, eds.) Patagonia. Natural History, Prehistory and Ethnography at the Uttermost End of the Earth. British Museum: London.

Morales, J.-V. \& Sanchis, A. 2009. The Quaternary fossil record of the genus Testudo in the Iberian Peninsula. Archaeological implications and diachronic distribution in the western Mediterranean. Journal of Archaeological Science 36: II52-62.

Mulvaney, J. \& Kamminga, J. I999. Prehistory of Australia. Smithsonian: Washington, DC.

Patou-Mathis, M. 2009. The subsistence behaviours of the Last Crimean Neanderthals, pp. 44I-62 in (M. Camps \& P. R. Chauhan, eds.) Sourcebook of Palaeolithic Transitions. Springer: New York.

Pesesse, D. 2010. Quelques repères pour mieux comprendre l'émergence du Gravettien en France. Bulletin de la Société Préhistorique Française I07 (3): 465-87.

Pétillon, J.-M. 2008. Des barbelures pour quoi faire? Réflexions préliminaires sur la fonction des pointes barbelées du Magdalénien supérieur. Palethnologie r: 69-102.

Pettitt, P. B. \& Pike, A. 2007. Dating European Palaeolithic cave art: progress, prospects, problems. Journal of Archaeological Method and Theory I4 (I): $27-47$.

Phoca-Cosmetatou, N. 2004. Site function and the "ibex-site phenomenon": myth or reality? Oxford Journal of Archaeology 23 (3): 217-42.

Rabeder, G. \& Pohar, V. 2004. Stratigraphy and chronology of the cave sediments from Potočka zijalka (Slovenia), pp. $235-46$ in (M. Pacher, V. Pohar \& G. Rabeder, eds.) Potočka Zijalka. Palaeontological and Archaeological Results of the Campaigns 1997-2000. Mitteilungen der Kommission für Quartärforschung der Österreischischen Akademie der Wissenchaften I3. Verlag der Österreischischen Akademie der Wissenchaften: Vienna.

Reimer, P. J., Baillie, M. G. L., Bard, E., Bayliss, A., Beck, J. W., Bertrand, C., Blackwell, P. G., Buck, C. E., Burr, G., Cutler, K. B., Damon, P. E., Edwards, R. L., Fairbanks, R. G., Friedrich, M., Guilderson, T. P., Hughen, K. A., Kromer, B., McCormac, F. G., Manning, S., Bronk Ramsey, C., Reimer, R. W., Remmele, S., Southon, J. R., Stuiver, M., Talamo, S., Taylor, F. W., Van der Plicht, J. \& Weyhenmeyer, C. E. 2009. Intcalog and Marineog radiocarbon age calibration curves, 0-50,000 years cal BP. Radiocarbon 5I (4): IIII-50.

Revedin, A., Aranguren, B., Becattini, R., Longo, L., Marconi, E., Mariotti Lippi, M., Skakun, N., Sinitsyn, A., Spiridonova, E. \& Svoboda, J. 2010. Thirty thousand-year-old evidence of plant food processing. Proceedings of the National Academy of Sciences USA I07 (44): I8,815-I9.

Rhodes, J. A. \& Churchill, S. E. 2009. Throwing in the Middle and Upper Palaeolithic: inferences from an analysis of humeral retroversion. Journal of Human Evolution 56: I-Io.

Richards, M. P. 2009. Stable isotope evidence for European Upper Palaeolithic human diets, pp. $25 \mathrm{I}^{-5} 57$ in (J.-J. Hublin \& M. P. Richards, eds.) The Evolution of Hominin Diets: Integrating Approaches to the Study of Palaeolithic Subsistence. Springer: New York.

Richards, M. P., Jacobi, R., Cook, J., Pettitt, P. B. \& Stringer, C. B. 2005. Isotope evidence for the intensive use of marine foods by Late Upper Palaeolithic humans. Journal of Human Evolution 49:390-4.

Richter, D., Tostevin, G., Škrdla, P. \& Davies, W. 2009. New radiometric ages for the Early Upper Palaeolithic type locality of Brno-Bohunice (Czech Republic): comparison of OSL, IRSL, $\mathrm{TL}$ and ${ }^{14} \mathrm{C}$ dating results. Journal of Archaeological Science $3^{6:}$ 708-20.

Rink, W. J., Schwarcz, H. P., Lee, H. K., Rees-Jones, J., Rabinovich, R. \& Hovers, E. 200I. Electron Spin Resonance (ESR) and Thermal Ionization Mass Spectrometric (TIMS) ${ }^{23^{\circ}} \mathrm{Th} /{ }^{234} \mathrm{U}$ dating of teeth in Middle Palaeolithic layers at Amud Cave, Israel. Geoarchaeology I6 (6): 70I-I7.

Rougier, H., Milota, Ş., Rodrigo, R., Gherase, M., Sarcina, L., Moldovan, O., Zilhão, J., Constantin, S., Franciscus, R. G., Zollikofer, C. P. E., Ponce de León, M. \& Trinkaus, E. 2007. Peştera cu Oase 2 and the cranial morphology of early modern Europeans. Proceedings of the National Academy of Sciences USA I04 (4): II65-70.

Russ, H. \& Jones, A. G. 2009. Late Upper Palaeolithic fishing in the Fucino Basin, central Italy: a detailed analysis of the remains from Grotta di Pozzo. Environmental Archaeology I4 (2): 155-62.

Sánchez-Goñi, M. F. \& Harrison, S. 2oro. Millennial-scale climate variability and vegetation changes during the Last Glacial: concepts and terminology. Quaternary Science Reviews 29: $2823-7$.

Sanchis, A. \& Fernández, J. 2008. Procesado y consumo antrópico de conejo en la Cova del Bolomor (Tavernes de la Valldigna, Valencia). El nivel XVIIc (ca $350 \mathrm{ka}$ ). Complutum I9 (I): 25-46.

Schmitz, R. W. (ed.) 2006. Neanderthal 1856-2006. Philipp von Zabern: Mainz.

Semal, P., Rougier, H., Crevecoeur, I., Jungels, C., Flas, D., Hauzeur, A., Maureille, B., Germonpré, M., Bocherens, H., Pirson, S., Cammaert, L., de Clerck, N., Hambucken, A., Higham, T., Toussaint, M. \& van der Plicht, J. 2009. New data 
on the Late Neandertals: direct dating of the Belgian Spy fossils. American Journal of Physical Anthropology I38: 42I-8.

Sepulchre, P., Ramstein, G., Kageyama, M., Vanhaeren, M., Krinner, G., Sánchez-Goñi, M.-F. \& d'Errico, F. 2007. H4 abrupt event and late Neanderthal presence in Iberia. Earth and Planetary Science Letters 258: 283-92.

Shea, J. J. 2006. The origins of lithic projectile point technology: evidence from Africa, the Levant, and Europe. Journal of Archaeological Science 33: 823-46.

Shea, J. J. \& Sisk, M. L. 20I0. Complex projectile technology and Homo sapiens dispersal into western Eurasia. PalaeoAnthropology 2010: 100-22.

Sinitsyn, A. A. 2003. The most ancient sites of Kostenki in the context of the Initial Upper Palaeolithic of northern Eurasia, pp. 89-107 in (J. Zilhão \& F. d'Errico, eds.) The Chronology of the Aurignacian and of the Transitional Technocomplexes: Dating, Stratigraphies, Cultural Implications. Instituto Português de Arqueologia: Lisbon.

Sitlivy, V., Sobczyk, K. \& Zieba, A. (eds.) 2008. Middle and Early Upper Palaeolithic of the Kraków Region. Piekary IIa, Royal Museums of Art and History: Brussels.

Soffer, O. 1989. Storage, sedentism, and the Eurasian Palaeolithic record. Antiquity 63: 719-32.

Soffer, O., Adovasio, J. M. \& Hyland, D. C. 2000. The "Venus" figurines. Current Anthropology 4I (4): 5II-37.

Soffer, O., Adovasio, J. M., Kornietz, N. L., Velichko, A. A., Gribchenko, Y. N., Lenz, B. R. \& Suntsov, V. Y. I997. Cultural stratigraphy at Mezhirich, an Upper Palaeolithic site in Ukraine with multiple occupations. Antiquity 7I: 48-62.

Soficaru, A., Dobos, A. \& Trinkaus, E. 2006. Early modern humans from the Peştera Muierii, Baia de Fier, Romania. Proceedings of the National Academy of Sciences USA I03 (46): 17, I96-20I.

Soficaru, A., Petrea, C., Dobos, A. \& Trinkaus, E. 2007. The human cranium from the Peştera Cioclovina Uscată, Romania. Current Anthropology 48 (4): 6II-I9.

Speth, J. 2004. News flash: negative evidence convicts Neanderthals of gross mental incompetence. World Archaeology 36 (4): $519-26$.

Stevens, R., O'Connell, T. C., Hedges, R. E. M. \& Street, M. 2009. Radiocarbon and stable isotope investigations at the central Rhineland sites of Gönnersdorf and Andernach-Martinsberg, Germany. Journal of Human Evolution 57: 13I-48.

Stiner, M. 1999. Palaeolithic mollusc exploitation at Riparo Mocchi (Balzi Rossi, Italy): food and ornaments from the Aurignacian through the Epigravettian. Antiquity 73: 735-54.

200I. Thirty years on the "Broad Spectrum Revolution" and Palaeolithic demography. Proceedings of the National Academy of Sciences USA 98 (I3): 6993-6.

Stiner, M. C., Munro, N. D. \& Surovell, T. A. 2000. The tortoise and the hare: small-game use, the broad-spectrum revolution, and Palaeolithic demography. Current Anthropology 4I (I): 39-73.

Straus, L. G. 1987. Upper Palaeolithic ibex hunting in Southwest Europe. Journal of Archaeological Science I4: $\mathrm{I}_{3}-78$.

(ed.) 1995. Les derniers chasseurs de rennes du monde pyrénéen. L'abri Dufaure: un gisement tardiglaciaire en Gascogne. Mémoires de la Société Préhistorique Française 22: Paris.

2005. The Upper Palaeolithic of Cantabrian Spain. Evolutionary Anthropology I4: 145-58.

Straus, L. G., González-Morales, M., Fano-Martínez, M. \& GarcíaGelabert, M. P. 2002. Last Glacial human settlement in eastern Cantabria (northern Spain). Journal of Archaeological Science 29: I403-I4.
Street, M., Terberger, T. \& Orschiedt, J. 2006. A critical review of the German Palaeolithic hominin record. Journal of Human Evolution 5I: 55I-79.

Stringer, C., Finlayson, J. C., Barton, R. N. E., Fernández-Jalvo, Y., Caceres, I., Sabin, R. C., Rhodes, E. J., Currant, A. P., Rodríguez-Vidal, J., Giles-Pacheco, F. \& Riquelme-Cantal, J. A. 2008. Neanderthal exploitation of marine mammals in Gibraltar. Proceedings of the National Academy of Sciences USA I05 (38): 14,319-24.

Svoboda, J. 2007. The Gravettian on the Middle Danube. Paléo I9: 203-20.

2008. The Upper Palaeolithic burial area at Prědmostí: ritual and taphonomy. Journal of Human Evolution 54: 15-33.

Svoboda, J. \& Bar-Yosef, O. (eds.) 2003. Stránská skála. Origins of the Upper Palaeolithic in the Brno Basin, Moravia, Czech Republic. American School of Prehistoric Research Bulletin 47: Cambridge, MA.

Szmidt, C. C., Brou, L. \& Jaccottey, L. 20I0. Direct radiocarbon (AMS) dating of split-based points from the (Proto)Aurignacian of Trou de la Mère Clochette, northeastern France. Implications for the characterization of the Aurignacian and the timing of technical innovations in Europe. Journal of Archaeological Science 37: 3320-37.

Terberger, T. \& Street, M. 2002. Hiatus or continuity? New results for the question of pleniglacial settlement in central Europe. Antiquity 76: 69I-8.

Teschler-Nicola, M. (ed.) 2006. Early Modern Humans at the Moravian Gate: The Mladeč Caves and Their Remains. Springer-Verlag: Vienna.

Teyssandier, N. 2008. Revolution or evolution: the emergence of the Upper Palaeolithic in Europe. World Archaeology 40 (4): 493-519.

Tiffagom, M. 2006. De la Pierre à L'Homme. Essai sur une paléoanthropologie solutréenne. Études et Recherches Archéologiques de l'Université de Liège II3: Liège.

Torres, T., Ortiz, J. E., Grün, R., Eggins, S., Valladas, H., Mercier, N., Tisnérat-Laborde, N., Juliá, R., Soler, V., Martínez, E., Sánchez-Moral, S., Cañaveras, J. C., Lario, J., Badal, E., Lalueza-Fox, C., Rosas, A., Santamaría, D., de la Rasilla, M. \& Fortea, J. 2010. Dating of the hominid (Homo neanderthalensis) remains accumulation from El Sidrón Cave (Piloña, Asturias, North Spain): an example of a multimethodological approach to the dating of Upper Pleistocene sites. Archaeometry 52 (4): 680-705.

Trinkaus, E. 2005a. Early modern humans. Annual Review of Anthropology 34: 207-30.

2005b. The adiposity paradox in the Middle Danubian Gravettian. Anthropologie 43 (2): IOI-9.

2007. European early modern humans and the fate of the Neandertals. Proceedings of the National Academy of Sciences USA I04 (I8): 7367-72.

2008. Behavioral implications of the Muierii I early modern human scapula. Annuaire Roumain d'Anthropologie 45: 27-4I.

Trinkaus, E., Bailey, S. \& Zilhão, J. 200I. Upper Palaeolithic human remains from the Gruta do Caldeirão, Tomar, Portugal. Revista Portuguesa de Arqueologia 4 (2): 5-17.

Trinkaus, E. \& Buzhilova, A. P. 2010. The death and burial of Sunghir I. International Journal of Osteoarchaeology. DOI: I0.I002/ Oa.I227.

Trinkaus, E., Moldovan, O., Milota, Ş., Bîlgãr, A., Sarcina, L., Athreya, S., Bailey, S. E., Rodrigo, R., Mircea, G., Higham, T., Bronk Ramsey, C. H. \& van der Plicht, J. 2003. An early modern 
human from the Peştera cu Oase, Romania. Proceedings of the National Academy of Sciences USA Ioo: II,23I-6.

Trinkaus, E. \& Svoboda, J. 2006. Early Modern Human Evolution in Central Europe: The People of Dolní Věstonice and Pavlov. Oxford University Press: Oxford.

Valladas, H., Clottes, J., Geneste, J.-M., García, M. A., Arnold, M., Cachier, H. \& Tisnérat-Laborde, N. 200I. Evolution of prehistoric cave art. Nature 4I3:479.

Valladas, H., Mercier, N., Froget, L., Hovers, E., Kimbel, W. H. \& Rak, Y. 1999. TL dates for the Neanderthal site of the Amud Cave, Israel. Journal of Archaeological Science 26: 259-68.

Vanhaeren, M. \& d'Errico, F. 200r. La parure de l'enfant de la Madeleine et du site éponyme (fouilles Peyrony). Un nouveau regard sur l'enfance au Paléolithique supérieur. Paléo I3: 20I-40.

2002. The body ornaments associated with the burial, pp. I5486 in (J. Zilhão \& E. Trinkaus, eds.) Portrait of the Artist as a Child. The Gravettian Human Skeleton from the Abrigo do Lagar Velho and Its Archeological Context. Trabalhos de Arqueologia 22, Instituto Português de Arqueologia: Lisbon.

2006. Aurignacian ethno-linguistic geography of Europe revealed by personal ornaments. Journal of Archaeological Science 33: $1105-28$.

Velichko, A. A. \& Zelikson, E. M. 2005. Landscape, climate and mammoth food resources in the East European Plain during the Late Palaeolithic epoch. Quaternary International I26-8: I37-5I.

Villa, P. \& Soriano, S. 20ro. Hunting weapons of Neanderthals and early modern humans in South Africa: similarities and differences. Journal of Anthropological Research 66: 5-38.

Villa, P., Soriano, S., Teyssandier, N. \& Wurz, S. 2010. The Howiesons Poort and MSA III at Klasies River main site, Cave IA. Journal of Archaeological Science 37: 630-55.

Villotte, S., Churchill, S. E., Dutour, O. J. \& Henry-Gambier, D. 20Io. Subsistence activities and the sexual division of labor in the European Upper Palaeolithic and Mesolithic: evidence from upper limb enthesopathies. Journal of Human Evolution 59: $35-43$.

Vishnyatsky, L. B. \& Nehoroshev, P. E. 2004. The beginning of the Upper Palaeolithic on the Russian Plain, pp. 80-96 in (P. J. Brantingham, S. L. Kuhn \& K. W. Kerry, eds.) The Early Upper Palaeolithic beyond Western Europe. University of California Press: Berkeley.

Wadley, L. \& Mohapi, M. 2008. A segment is not a monolith: evidence from the Howiesons Poort of Sibudu, South Africa. Journal of Archaeological Science 35: 2594-605.

Wagner, E. I983. Das Mittelpaläolithikum der Großen Grotte bei Blaubeuren (Alb-Donau-Kreis). Konrad Theiss Verlag: Stuttgart.

Walker, M. J., Gibert, J., López, M. V., Lombardi, A. V., PérezPérez, D. A., Zapata, J., Ortega, J., Higham, T., Pike, A., Schwenninger, J.-L., Zilhão, J. \& Trinkaus, E. 2008. Late Neandertals in southeastern Iberia: Sima de las Palomas del Cabezo Gordo, Murcia, Spain. Proceedings of the National Academy of Sciences USA I05 (52): 20,63 I-6.

Weniger, G. 1982. Wildbeuter und ihre Umwelt. Ein Beitrag zum Magdalénien Südwestdeutschlands aus ökologischer und ethnoarchäologischer Sicht. Institut für Urgeschichte der Universität Tübingen: Tübingen.

1987. Magdalenian settlement patterns and subsistence in central Europe: the southwestern and central German cases, pp. 20I-I5 in (O. Soffer, ed.) The Pleistocene Old World: Regional Perspectives. Plenum Press: New York.

Wenzel, S. 2007. Neanderthal presence and behaviour in central and northwestern Europe during MIS 5e, pp. 173-93 in (F. Sirocko, M. Claussen, M. F. Sánchez-Goñi \& T. Litt, eds.) The Climate of Past Interglacials. Elsevier: Amsterdam.

White, R. 1999. Intégrer la complexité sociale et opérationnelle: la construction matérielle de l'identité sociale à Sungir, pp. 3I9-3I in (M. Julien, A. Averbouh, D. Ramseyer, C. Bellier, D. Buisson, P. Cattelain, M. Patou-Mathis \& N. Provenzano, eds.) Préhistoire d'os. Recueil d'études sur l'industrie osseuse préhistorique offert à Henriette Camps-Fabrer. Aix-en-Provence, Université de Provence: Aix-en-Provence.

2003. Prehistoric Art: The Symbolic Journey of Humankind. Abrams: New York.

Wobst, M. 1974. Boundary conditions for Palaeolithic social systems: a simulation approach. American Antiquity 39: $147-78$.

1976. Locational relationships in Palaeolithic society. Journal of Human Evolution 5: 49-58.

Wolff, E. W., Chappellaz, J., Blunier, T., Rasmussen, S. O. \& Svensson, A. 20I0. Millennial-scale variability during the last glacial: the ice core record. Quaternary Science Reviews 29: 2828-38.

Wolpoff, M., Mannheim, B., Mann, A., Hawks, J., Caspari, R., Rosenberg, K. R., Frayer, D. W., Gill, G. W. \& Clark, G. 2004. Why not the Neandertals? World Archaeology 36 (4): 527-46.

Zilhão, J. I993. Le passage du Paléolithique moyen au Paléolithique supérieur dans le Portugal, pp. 127-45 in (V. Cabrera, ed.) El Origen del Hombre Moderno en el Suroeste de Europa. Universidad Nacional de Educación a Distancia: Madrid.

1997. O Palaeolítico Superior da Estremadura portuguesa. 2 vols. Colibri: Lisbon.

200I. Anatomically Archaic, Behaviorally Modern: The Last Neanderthals and Their Destiny. Stichting Nederlands Museum voor Anthropologie en Praehistoriae: Amsterdam.

2005. Burial evidence for the social differentiation of age classes in the Early Upper Palaeolithic, pp. 23I-4I in (D. Vialou, J. Renault-Miskovsky \& M. Patou-Mathis, eds.) Comportements des hommes du Paléolithique moyen et supérieur en Europe: territoires et milieux. Actes du Colloque du GDR 1945 du CNRS, Paris, 8-Io janvier 2003. Études et Recherches Archéologiques de l'Université de Liège IIr: Liège.

2006. Neandertals and moderns mixed, and it matters. Evolutionary Anthropology 15: 183-95.

2007. The emergence of ornaments and art: an archaeological perspective on the origins of behavioural "modernity". Journal of Archaeological Research 15: I-54.

2009. Szeletian, not Aurignacian: a review of the chronology and cultural associations of the Vindija Gi Neandertals, pp. 407-26 in (M. Camps \& P. R. Chauhan, eds.) A Sourcebook of Palaeolithic Transitions. Springer: New York.

20II. Aliens from outer time? Why the "Human Revolution" is wrong, and where do we go from here, pp. 33I-66 in (S. Condemi \& G.-C. Weniger, eds.) Continuity \& Discontinuity in the Peopling of Europe: One Hundred Fifty Years of Neanderthal Studies. Springer (Vertebrate Palaeobiology and Palaeoanthropology Series): Dordrecht.

Zilhão, J., Angelucci, D., Badal-García, E., d'Errico, F., Daniel, F., Dayet, L., Douka, K., Higham, T. F. G., Martínez-Sánchez, M. J., Montes-Bernárdez, R., Murcia-Mascarós, S., PérezSirvent, C., Roldán-García, C., Vanhaeren, M., Villaverde, V., 
Wood, R. \& Zapata, J. 2010a. Symbolic use of marine shells and mineral pigments by Iberian Neandertals. Proceedings of the National Academy of Sciences USA 107 (3): 1023-8.

Zilhão, J., Angelucci, D., Badal, E., Lucena, A., Martín, I., Martínez, S., Villaverde, V. \& Zapata, J. 20Ioc. Dos abrigos del Palaeolítico superior en Rambla Perea (Mula, Murcia), pp. $137-48$ in (X. Mangado, ed.) El Paleolítico superior peninsular. Novedades del siglo XXI. Universidad de Barcelona: Barcelona.

Zilhão, J., Aubry, T., Carvalho, A. F., Baptista, A. M., Gomes, M. V. \& Meireles, J. 1997. The rock art of the Côa Valley (Portugal) and its archaeological context. Journal of European Archaeology 5 (I): 7-49.

Zilhão, J., Davis, S. J. M., Duarte, C., Soares, A. M. M., Steier, P. \& Wild, E. 20rob. Pego do Diabo (Loures, Portugal): Dating the emergence of anatomical modernity in westernmost Eurasia. PLoS ONE 5 (I); e888o (doi:Io.I37I/journal. pone.0008880).
Zilhão, J. \& d'Errico, F. 1999. The chronology and taphonomy of the earliest Aurignacian and its implications for the understanding of Neanderthal extinction. Journal of World Prehistory I3 (I): I-68.

2003. An Aurignacian "Garden of Eden" in southern Germany? An alternative interpretation of the Geissenklösterle and a critique of the Kulturpumpe model. Paléo I5: 69-86.

Zilhão, J. \& Trinkaus, E. (eds.) 2002. Portrait of the Artist as a Child: The Gravettian Human Skeleton from the Abrigo do Lagar Velho and Its Archeological Context. Trabalhos de Arqueologia 22. Instituto Português de Arqueologia: Lisbon.

Zilhão, J., Trinkaus, E., Constantin, S., Milota, Ş., Gherase, M., Sarcina, L., Danciu, A., Rougier, H., Quilès, J. \& Rodrigo, R. 2007. The Peştera cu Oase people, Europe's earliest modern humans, pp. 249-62 in (P. Mellars, K. Boyle, O. Bar-Yosef \& C. Stringer, eds.) Rethinking the Human Revolution. McDonald Institute for Archaeological Research: Cambridge. 